DOI: $10.1002 /(($ please add manuscript number $))$

Article type: (Full Paper)

\title{
Novel synthesis and characterization of doxycycline-loaded gold nanoparticles. The golden doxycycline for antibacterial applications.
}

Maroua Ben Haddada ${ }^{1}$, Katy Jeannot ${ }^{2}$, Jolanda Spadavecchia $^{1} *$

${ }^{1}$ CNRS, UMR 7244, CSPBAT, Laboratoire de Chimie, Structures et Propriétés de Biomateriaux et d'Agents Therapeutiques Université Paris 13, Sorbonne Paris Cité, Bobigny, France

${ }^{2}$ Laboratoire de Bactériologie, Centre National de Référence (CNR) de la Résistance aux Antibiotiques, Centre Hospitalier Régional Universitaire (CHRU) de Besançon, UMR4269 "Chrono-Environnement", Boulevard Fleming, 25030 Besançon, France. 


\begin{abstract}
Doxycycline (DOXY) is a tetracycline antibiotic with a potent antibacterial activity against a wide variety of bacteria. One potential strategy to enhance the penetration and the antibacterial activity of antibiotics is the use of nanotechnology. In this work, we report an innovative synthesis of a stable PEG-AuNPs loaded with DOXY. To the best of our knowledge, this is the first report on the combination of DOXY with gold nanoparticles as polymeric complex. The obtained nanoparticles were fully characterized by transmission electron microscopy (TEM), dynamic light scattering (DLS), zeta-potential, UV-Vis and Raman spectroscopy. The stability and sustained activity of the drug in nanoparticles was determined on a panel of Gram positive and Gram negative bacteria in comparison with the native form of the drug. This combined therapeutic agent restored the susceptibility of DOXY and showed an antibacterial activity against major human pathogens (Staphylococcus aureus, Escherichia coli, Klebsiella pneumoniae, Pseudomonas aeruginosa, and Acinetobacter baumannii). Synergy of antibiotic with nanoparticles is quite promising, notably for antibiotic resistant strains. The antibacterial effect of combination of DOXY with gold nanoparticles was conserved despite the production of antibiotic resistance mechanisms in all the strains tested. Doxycycline-loaded nanoparticles could be used efficiently for antibacterial therapy, possibly against a large number of bacterial species.
\end{abstract}

KEYWORDS: AuNPs, doxycycline, antibiotic conjugation, antibacterial effect. 


\section{INTRODUCTION}

Antibiotic resistance has been compared to as "the silent tsunami facing modern medicine",[1]. The broad use and the improper administration of antibiotics had make bacteria able to develop resistance against them. Many conventional antimicrobials became obsolete due to the emergence of multidrug-resistant pathogens ${ }^{[1]}$. The chemical modification of antibiotic scaffolds to evade overcome bacterial resistance and to synthesize new antibiotics of high efficiency is time consuming and is often not economically feasible. Moreover, the antibiotic dosage often prescribed in some therapy is much higher leading to harmful side effects. For a successful antibiotic therapy, the antibiotic dose should be reduced and the stability should be increased to make the usage economical. One potential strategy to overcome this problem is the use of nanotechnology ${ }^{[2]}$. Several studies have reported the antimicrobial activity of

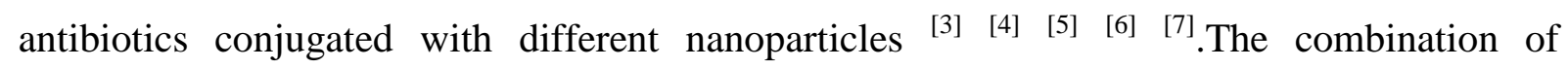
antibiotics to inorganic nanoparticles might enhance their antimicrobial effectiveness against multidrug resistant bacteria ${ }^{[8]}$. Moreover, nanoparticles were shown to take up by phagocytic cells that improves the delivery of antibiotics for the treatment of intracellular infections ${ }^{[9]}$.

Gold and silver nanoparticles, as drug carriers, possess the potential to increase drug concentration at infected sites, combat its side effects and target the drug to the appropriate site of action ${ }^{[10]}$. As examples, Gu et al. have reported the enhanced antimicrobial activity of vancomycin coated gold nanoparticles on vancomycin resistant enterococci ${ }^{[11]}$. Saha et al. demonstrated that the in vitro bactericidal activity of gold nanoparticles conjugated ampicillin, streptomycin and kanamycin were more efficient compared to their respective free forms ${ }^{[12]}$. Deng et al have shown the synergic effect of amoxicillin with silver nanoparticles against Escherichia coli ${ }^{[13]}$. Rai et al. used cefaclor as both reducing and capping agent to produce spherical gold nanoparticles and showed a potent activity against both Gram-positive and Gram-negative bacteria ${ }^{[3]}$. Doxycycline (DOXY) (Scheme S1 Supporting Informations) has 
been recognized as a family of tetracycline antibiotics of very efficient antimicrobial activity $^{[14]}{ }^{[15]}$. The chemical structure of DOXY is very similar to doxorubicin (DOX) $)^{[16]}$. Both molecules contains a tetracyclic molecule, including planar and aromatic hydroxyl anthraquinone rings, which function as chromophore, responsible for therapeutic activity ${ }^{[17]}$ [14]. However, the formulation in use has shown dramatic side effects as their low bioavailability ${ }^{[15]}$, is responsible for delivery problems and consequently of systemic toxicity that limited their medical application ${ }^{[18]}$. Recently, J. Spadavecchia et al. have synthetized an original nanovector based on doxorubicin-gold-complex, by a chelation reaction in which, the drug was complex with tetrachloauric acid $\left(\mathrm{HAuCl}_{4}\right)$ and polymer molecules before reduction to final nanovector (DOX IN AuNPs) ${ }^{[16]}$. The same authors have also studied the mechanism of hybrid nanoparticles using doxorubicin capped onto gold nanoparticles with biocompatible polymers as capping agent (DOX-ON AuNPs) in order to compare the different activity of both nanovectors ${ }^{[19]}{ }^{[20]}$, and their remarkable interest in therapeutic activity to in vitro model of Pancreatic Ductal Adeno Carcinoma (PDAC) ${ }^{[19]}{ }^{[16]}$.

In this paper, we combined gold nanoparticles (AuNPs) with DOXY by three chemical different methodologies (DOXY-AuNPs, DOXY ON-AuNPs, DOXY IN-AuNPs) and, evaluated the antimicrobial effect of these hybrids on several bacterial species in the presence of gold nanoparticles (AuNPs) synthetized. Therefore, the development of a simple and fast method to improve the activity of DOXY and oxytetracycline has become increasingly attractive $^{[13]}$.

The combination DOXY ON AuNPs exhibited the lower MICs $(\leq 2 \mathrm{mg} / \mathrm{L})$ in comparison with native DOXY in all species tested. Interestingly, the DOXY ON AuNPs was stable against the major resistance mechanisms to antibiotics acquired by human pathogen bacteria. 


\section{RESULTS AND DISCUSSION}

\section{Formation mechanism and physico-chemical characterization of Doxycycline}

Nanoparticles (DOXY-Au NPs, DOXY IN-Au NPs, DOXY ON-Au NPs,)

In the last years many authors have produced antibiotic mediated synthesis of gold and silver nanoparticles with potent antimicrobial activity and their application in antimicrobial coatings [3].

Other authors have designed a nanocomposite based on DOXY -loaded polymeric nanoparticles in order to improve drug delivery and efficacy with considerable antimicrobial activity $^{[6]}{ }^{[21]}$. In our case, the synthesis of DOXY-AuNPs (Scheme 1 A) was carried out at room temperature by reduction of gold ions $\left(\mathrm{AuCl}_{4}{ }^{-}\right)$using DOXY as reducing and capping agent on the growth process. A fast reduction in the time of gold ion, was observed when the reaction was performed at room temperature under basic conditions $(\mathrm{NaOH})$. It is well established that amine and carbonyl groups can easily chelate and transfer electrons to gold ions $\left(\mathrm{Au}^{3+}\right)$, leading to the formation of $\mathrm{Au}^{0}$ (nuclei)/ $\mathrm{Au}$-amine complexes via simple aminecarbonyl chemistry ${ }^{[16]}{ }^{[22]}{ }^{[23]}$. Pending the reduction of gold ions $\left(\mathrm{AuCl}_{4}{ }^{-}\right)$exploiting DOXY drives to a rise in the rate of reduction of the gold ions, which favors an enhanced nucleation rate with the formation of a gold grains ${ }^{[24]}{ }^{[25]}$. Gold ions are consequently reduced on the surface of gold nuclei, therefore involving the achievement of spherical gold nanoparticles of smaller sizes, which are embedded and stabilized by DOXY (Scheme 1 A and scheme 2). In order to improve the stability and biological activity of the gold nanoparticles in object, we decided to apply some modification to original synthesis, through the methodology ON and

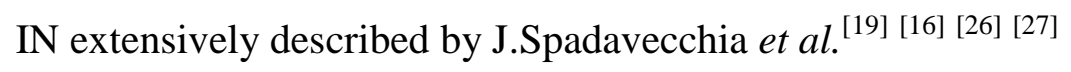

Scheme 1 B showed a chemical procedure, named methodology IN, in which DOXY and PEG both participate actively to the stabilization of AuNPs via chelation between their chetone and amino groups with chloride auric ions. Chelation sites include the $\beta$-diketone 
system (positions 11 and 12), the enol (positions 1 and 3) and carboxamide (position 2) groups of the A ring (see figure S1) ${ }^{[28]}$.

The stacking process by electrostatic interaction between polymer (PEG) and DOXY-Au complex and final reduction in the presence of $\mathrm{NaBH}_{4}$ are responsible of final growth process and colloidal stabilization as previously described ${ }^{[16]}{ }^{[26]}$ (scheme 1B). The third synthetic protocol, named methodology ON was depict in scheme 1C and performed in two main steps: 1) firstly, PEG-capped AuNPs were synthetized (PEG-AuNPs) and 2) further conjugated to DOXYL by carbodiimide chemistry between carboxylic group of PEG diacide onto AuNPs and amino group of DOXY as schematically showed. Based on our chemical design, the PEG-AuNPs appertain to the category of nanomedicines in which the drug payload is promptly conjugated to the nanoparticle surface via degradable covalent bond ${ }^{[19]}$. The amide group binding the PEG chains to the DOXY molecules was designed so that it could be cleaved under the specific conditions in the cytoplasm releasing the drug in protonate form ${ }^{[5,29]}$. At present it is recognized that the efficacy of antibacterial drugs is in many cases hampered by low antimicrobial concentration due to their poor bioavailability at the disease site.

All nanoparticles of our chemical procedure were extensively characterized by UV-Vis absorption spectroscopy, TEM and Raman spectroscopy. When DOXY was mixed to the $\mathrm{AuCl}_{4}{ }^{-}$solution, in the presence of $\mathrm{NaOH}$, the formation of spherical gold nanoparticles (DOXY-AuNPs) of about $6.5 \pm 0.7 \mathrm{~nm}$ was observed by TEM (Figure 1B-a).

UV-Vis absorption spectroscopy analysis of DOXY-AuNPs products (Figure 1A; dark cyan) showed a clear band at $530 \mathrm{~nm}$. The band positions are compared with spectroscopic band observed with individual DOXY molecules. This means that the DOXY could be present inside the solution as well as another compound. Moreover, the individual DOXY exhibits two pronounced UV-Vis absorption peaks at $346 \mathrm{~nm}$ and $274 \mathrm{~nm}$. This 
spectroscopical finger print was associated to $\pi-\pi^{*}$ electronic transitions due to interactions between the DOXY ring and $\mathrm{AuCl}_{4}{ }^{-}$ions ${ }^{[30]}$ making a clear demonstration of the complex formation. In agreement with previously studies ${ }^{[16][26] ~[27]}$, we arrogate that this band is due to electronic delocalization of aromatic ring and HOMO-LUMO transition and clear up that DOXY was really involved into the nucleation process and builds a complex with Au.

In the case of DOXY IN-AuNPs synthesis, PEG molecules improved the reduction process by interacting with the $\mathrm{DOXY}-\mathrm{AuCl}_{4}{ }^{-}$complex, stabilizing such complex and subsequently acting as surfactant in the nucleation and growth of the nanostructures. In particular, the formation of gold nanoparticles from $\mathrm{AuCl}_{4}{ }^{-}$can be recapitulated in three steps (see scheme 3):

(1) Formation of DOXY-PEG diacid complex; (2) initial reduction of metal ions improved by DOXY and dicarboxylic acid-terminated PEG in aqueous solutions to form gold clusters; (3) adsorption of DOXY-PEG diacid complex on the surface of gold clusters and reduction of metal ions in that vicinity with consequently growth of gold particles and colloidal stabilization by molecules of PEG polymers.

Interactions between $\mathrm{AuCl}_{4}{ }^{-}$ions and mixture of DOXY-PEG diacid molecules (attractive ion-dipole interactions $v s$ repulsive interactions due to hydrophobicity) are decisive in order to check the competition between $\mathrm{AuCl}_{4}{ }^{-}$reduction, and the final particle size ${ }^{[31]}$.

DOXY IN-AuNPs absorption spectrum exhibits a small peak at $310 \mathrm{~nm}$ and a second one centered at $540 \mathrm{~nm}$ (Figure 1A red line). This latter peak is assigned to the localized surface plasmon of the nanoparticle with diameter of $23 \mathrm{~nm}$ embedded in PEG environment as expected ${ }^{[32]}$. The AuNPs thus formed were characterized by TEM and have spherical shape (Figure 1B-b) with a diameter close to $23 \pm 4.2 \mathrm{~nm}$, confirmed by the hydrodynamic 
diameter measured by zetasizer (Table 1 in Supporting Information). Previously J.Spadavecchia et al. have reported the synthesis of similar nanostructures using dicarboxylic PEG $^{[31,33][34]}$ obtaining PEG AuNPs as building block of nanovectors ${ }^{[19] ~[16] ~[26] ~[27] ~}$.

On the basis of previous studies, when DOXY was conjugate to PEG AuNPs by carbodiimide chemistry to form DOXY ON-AuNPs, we obtain a nanoconjugate in which DOXY was grafted on the surface of polymer-nanoparticle, taking on a different chemical and conformation ( see scheme 4). We observe a red shift plasmon peak from $515 \mathrm{~nm}$ relative at PEG AuNPs (Figure 1 A -black line) to $525 \mathrm{~nm}$ (Figure 1 A -green line) with a different chemical and steric arrangement between PEG and DOXY onto the surface of AuNPs that influences the final size of the nanoparticles.

TEM images show spherical gold nanoparticles with a mean diameter of about $13 \mathrm{~nm} \pm 1.2$ nm (Figure 1B-c). In addition, the bright red color of the obtained nanoparticles and the UVVis spectra remain unaltered after storage for more than three months at room temperature validating the formation of stable particle suspension.

The Raman spectra of free DOXY (control), DOXY-AuNPs, DOXY IN-AuNPs and DOXY ON-AuNPs in water exhibit many bands in the region $400-2000 \mathrm{~cm}^{-1}$ (Figure 2). The wide band observed around $1600 \mathrm{~cm}^{-1}$ on the raman spectra is assigned to the water. The bands for DOXY (Figure 2 blue line) were assigned in the following manner: frequencies at $1677 \mathrm{~cm}^{-1}$ and $1537 \mathrm{~cm}^{-1}$ are related to the carbonyl and amino groups of the amide, respectively, in ring $\mathrm{A}$; bands at $1613 \mathrm{~cm}^{-1}$ and $1581 \mathrm{~cm}^{-1}$ correspond to the carbonyl groups in rings $\mathrm{A}$ and $\mathrm{C}$, respectively; the band at $1458 \mathrm{~cm}^{-1}$ is related to the $\mathrm{C}=\mathrm{C}$ skeleton vibration. The oxygen atoms on $\mathrm{C} 1$ and $\mathrm{C} 3$ may be equivalent because there was only one frequency at $1615 \mathrm{~cm}^{-1}$. The triplet peak at $430-459-493 \mathrm{~cm}^{-1}$ is due to the vibrations $\delta(\mathrm{OH} \ldots \mathrm{O}), v(\mathrm{OH} \ldots \mathrm{O})$ of the DOXY molecule. For instance, a double peaks at $1312-1270 \mathrm{~cm}^{-1}$ and $1175 \mathrm{~cm}^{-1}$ was assigned to $\mathrm{C}=\mathrm{O}$ carbonyl stretching and $\mathrm{C}-\mathrm{O}-\mathrm{C}$ stretching in backbone of DOXY. When 
DOXY chelate to $\mathrm{Au}^{3+}$ to form DOXY-AuNPs ( Figure 2 - dark cyan) in alkaline medium, we observed an apparition of the peaks at $1386 \mathrm{~cm}^{-1}$ due to $\mathrm{C}-\mathrm{O}$ plane deformation of amide group, $1542 \mathrm{~cm}^{-1}$ assigned to $v \mathrm{C}-\mathrm{C}$ stretching and a strong peak at $882 \mathrm{~cm}^{-1}$, due to $\mathrm{C}=\mathrm{O}$ group of quinolone. For instance, a double peak at $1312-1270 \mathrm{~cm}^{-1}$ is lowered. A triplet peak in the spectral region $430-493 \mathrm{~cm}^{-1}$ disappeared. These bands are due to variation of the steric conformation of the DOXY and become more prominent upon complexation, as described previously ${ }^{[33 a]}{ }^{[34]}$. These results were in part confirmed in DOXY IN-AuNPs, in which DOXY chelate to $\mathrm{Au}^{3+}$ in the presence of PEG diacid to form hybrid nanoparticles. The raman spectra clearly shows band changes of amide carbonyl and amino groups in ring A. Figure 2 red line showed an apparition of the peaks at $1423 \mathrm{~cm}^{-1}, 1370 \mathrm{~cm}^{-1}, 1284 \mathrm{~cm}^{-1}$, due to $\mathrm{C}-\mathrm{O}$ plane deformation of carboxylic acid, and $\mathrm{C}=\mathrm{O}$ carbonyl stretching of the $\mathrm{PEG}$. However, the peaks for amide $\mathrm{C}=\mathrm{O}$ of DOXY shifted from $1625-1657 \mathrm{~cm}^{-1}$ to $1633 \mathrm{~cm}^{-1}$ and those of $-\mathrm{NH}_{2}$ shifted from $1579 \mathrm{~cm}^{-1}$ to $1536 \mathrm{~cm}^{-1}$. These results suggest that the interaction of DOXY with PEG could take place through the amide $\mathrm{C}=\mathrm{O}$ in ring $\mathrm{A}$. A similar steric conformation of DOXY in hybrid nanoparticles (DOXY IN-AuNPs) compared to DOXY AuNPs was confirmed by a disappearance of triplet peak in the region $400-430 \mathrm{~cm}^{-1}$. These bands were assigned to DOXY aromatic rings vibrations and to those of $\mathrm{C}=\mathrm{O}$ and hydroxyl groups in the DOXY molecule. It is already previously described that most of the Raman bands of molecules can be significantly increased by their proximity to the surface AuNPs ${ }^{[16]}$. Thus, the enhancement of such bands is herein demontrated as a trial of the drug loading into AuNPs, as well as to their arrangement within the particles. When DOXY was grafted onto PEG-AuNPs, by carbodiimide chemistry to form DOXY ON AuNPs (Figure 2 green line), a strong spectroscopic variation was occurs. In particular we observed a SERS effect in the region $400-2000 \mathrm{~cm}^{-1}$. A double peak at $1462-1438 \mathrm{~cm}^{-1}$ is due to vibration $\mathrm{N}-\mathrm{H}$; the increase of the peaks at $1364-1318-1275 \mathrm{~cm}^{-1}$ is due to a different C-O plane deformation of 
carboxylic acid, and $\mathrm{C}=\mathrm{O}$ carbonyl stretching of the $\mathrm{PEG}$ backbone. This result was confirmed by the shift of the peak from $1175 \mathrm{~cm}^{-1}$ to $1182 \mathrm{~cm}^{-1}$, due to $\mathrm{C}-\mathrm{O}-\mathrm{C}$ vibration. The steric and chemical conformation of DOXY onto the surface of PEG AuNPs was demonstrated by a strong SERS effect in the peak at $982 \mathrm{~cm}^{-1}$ due to C-O plane deformation in the ring of DOXY and the apparition of triplet peaks in the region $430-500 \mathrm{~nm}$ due to the vibrations $\delta(\mathrm{OH} \ldots \mathrm{O}), v(\mathrm{OH} \ldots \mathrm{O})$ of the DOXY molecule. Based on these findings, we conclude that DOXY assumes three different chemical conformations on the basis of chemical protocol to form hybrid nanoparticles.

Stability of DOXY gold nanoparticles (DOXY-AuNPs, DOXY IN-AuNPs, DOXY ON$\operatorname{AuNPs):}$

The stability of DOXY gold nanoparticles in solution, pivotal a significant role in the clinical purposes $^{[35]}$ and was monitored by the Localized Surface Plasmon (LSP) band of the synthetized AuNPs (scheme 1; Figure 1). Analysis was performed at $\mathrm{pH} 8$ and electrolytic conditions over a reasonable period of time (3 months). The synthesized AuNPs did show an almost negligible change in the LSP band position over a period of three- months at the $\mathrm{pH} 8$ (Figure S1 in the Supporting Information). The decrease in intensity of plasmon peak, is due to agglomeration phenomena owing the oxidation process. Zeta potential measurements confirmed the spectroscopic results, showing that DOXY ON-AuNPs and DOXY-AuNPs were colloidally stable at physiological $\mathrm{pH}$ (z-potential $=-25 \pm 0.5 \mathrm{mV}$ and $\mathrm{z}$-potential $=$ $-34 \pm 0.8 \mathrm{mV}$ with a PdI equal to 0.3) (Table 1). We suggest that DOXY ON-AuNPs enhanced stability was associated with the presence of the PEG coating. The zeta potential of DOXY IN -AuNPs products in fact was found equal to $-17.93 \pm 0.7 \mathrm{mV}$, indicating a mild dispersion. The negative zeta potential suggested the presence of free negative charges in the sample, probably associated to free chloride ions $\left(\mathrm{Cl}^{-}\right)$and/or 
ionisable functions, such as the phenolic groups on the DOXY molecules present in the Au (III)-DOXY complexes.

Drug loading and release of DOXY Nanoparticles (DOXY-Au NPs, DOXY IN-Au NPs, DOXY ON-Au NPs):

Previously, A. Kumar et al. have studied the process of loading of DOXY onto chitosan nanoparticles to improve drug delivery and treatment efficacy ${ }^{[6]}$. The effectiveness of a gradient loading system is highly dependent on the chemistry of the drug being loaded ${ }^{[36]}$. Gradient-loading systems in response to a $\mathrm{pH}$ gradient, have been developed for other antibacterial drugs, but differ from the method described in the current manuscript. We developed a novel loading methodology, resulting in pegylated nanoparticles with higher drug loading and longer retention times than passive aqueous capture ${ }^{[37]}$. Our loading efficiency is 10-40 times more efficient than the previously published methods ${ }^{[36][6]}$.

Previous formulations of DOXY in DPPC/cholesterol liposomes used mannose or glucose solutions at a $\mathrm{pH}$ of 6.0 as non ionic hydrating solutions, and these formulations have encapsulation efficiencies of nearly 10 -fold less than the sulfuric acid-loading technique ${ }^{[38]}$. The percentage of released drug is dependent on the initial drug concentration, and equilibrium between the soluble drug and precipitate follows a zero-order process if the drug precipitates in the liposome ${ }^{[39]}$. Tu et al. used an ammonium sulfate gradient-loading system to describe the liposomal loading of the drug based on the amount of ammonium ion in the liposomes and the initial amount of drug added ${ }^{[40]}$.

The successful loading ratio of DOXY onto PEG-AuNPs (DOXY ON-AuNPs) and complexed with $\mathrm{AuCl}_{4}{ }^{-}$and PEG diacid (DOXY-AuNPs, DOXY IN-AuNPs) were evidenced by the characteristic absorption peaks at $273 \mathrm{~nm}$ and $345 \mathrm{~nm}$ from DOXY (Figure S2-A Supporting information). The standard absorption of DOXY was plotted in the inset of 
figure (Figure S2-B Supporting information) according to UV-Vis absorbance spectra of DOXY at various concentrations. The loading efficiencies were estimated to be $86 \%$ with 8.7 $\mu \mathrm{g}$ present in $2.7 \times 10^{-8} \mathrm{~mol}$ of NPs (data not shown) for DOXY ON-AuNPs, $65 \%$ for DOXY IN-AuNPs, and 54\% for DOXY-AuNPs. DOXY releases were $\mathrm{pH}$ - and time-dependent (Figure 3 A-B). A sustained drug release was observed in the first $5 \mathrm{~h}$ for both drugs at $\mathrm{pH} 5$ and 8, which is highly favorable for drug delivery as the bacterial thrive in basic conditions. We presumed that the release of DOXY was checked by a ionic equilibrium between Au (III)PEG complexes trapped into AuNPs by the hydrophobic interactions between PEG chains and ionic drug. As previously described, the mechanism by which basic $\mathrm{pH}$ triggers drug release is probably associated to the presence of carboxylate groups in the chemical structure of PEG molecules. Such groups become dissociated in anionic form at basic $\mathrm{pH}$. This improve the electrostatic interactions occurring between PEG and drugs that stabilize the DOXY ON AuNPs structure.

We suppose that, the ionic strength and anionic form of DOXY onto PEG chains improve the water solubility of the drug molecules, taking advantage of the drug release from AuNPs. Indeed, a remarkable moiety of DOXY electrostatically binding onto dissociated complex is released, through PEG chain and diffusion phenomena ${ }^{[33 a, 41]}$.

\section{Extended spectrum of DOXY ON-AuNPs activity in bacteria}

It is well established that tetracyclines inhibit bacterial protein synthesis by preventing the association of aminoacyl tRNA with the bacterial ribosome ${ }^{[42]}{ }^{[43]}$. Therefore, to interact with their targets these molecules need to traverse one or more membrane systems depending on whether the susceptible organism is gram positive or gram negative. The extensive structureactivity studies have demonstrated that, the membrane-disrupting properties of the atypical tetracyclines are probably related to the relative planarity of the $\mathrm{B}, \mathrm{C}$, and $\mathrm{D}$ rings so that a 
lipophilic, non ionized molecule predominates. On interaction with the cell, the atypical tetracyclines are likely to be preferentially trapped in the hydrophobic environment of the cytoplasmic membrane, disrupting its function ${ }^{[43]}$.

The presence of surfactant molecules onto the surface of nanoparticles, are usually undesirable, due to their capacity to block adsorption sites ${ }^{[5]}$. Heloiza F. O. Silva et al. have showed, that polyvinyl alchol (PVP), play a key role in linking with DOXY onto silver nanoparticles $(\mathrm{AgNPs})^{[5]}$. They demonstrated, that less silver to be released, due to the layer size of the AgNPs and consequently, DOXY can release more easily followed the disruption of ATP production and an increase in DNA mutation ${ }^{[44]}$.

However, we have shown that PEG diacid played a paramount role in concentrating DOXY around the particle, which culminated in an increased bacteriostatic activity. To evaluate the antibacterial activity of the synthetized nanoparticles, we selected a panel of bacteria frequently involved in clinical infections, including Gram positive and Gram negative bacteria (Tables 1, and 2). The MICs of compounds were compared with reference antibiotics (amoxicillin, ceftazidime, and imipenem). Whichever the bacteria tested the lowest MICs was measured in presence of DOXY ON-AuNPs (Tables 1, and 2). The MICs of DOXY ONAuNPs were 8 to 16 fold lower than that unmodified DOXY in Gram positive and negative, even in DOXY intrinsically resistant bacteria like P. aeruginosa. It is worth noting that the MIC values of DOXY ON-AuNPs were similar to that of reference antibiotics such as amoxicillin in S. aureus $\left(\mathrm{ATCC}^{\circledR} 25923^{\mathrm{TM}}\right.$ ), and E. faecalis (JH2-2), and ceftazidime in P. aeruginosa (PAO1) and A. baumannii (CIP7010). Whereas the DOXY-AuNPs did not display antibacterial activity, the DOXY IN-AuNPs possessed a poor activity against Gram positive and negative bacteria. According to these results, we focused the susceptibility tests with DOXY ON-AuNPs, and DOXY IN-AuNPs. As antibiotic resistance is becoming a global critical issue particularly in ESKAPE pathogens including the species E. coli, S. aureus, 
K. pneumoniae, A. baumannii, P. aeruginosa, and E. aerogenes ${ }^{[45]}$, we determined the MICs of DOXY ON-AuNPs, and DOXY IN-AuNPs in several ESKAPE pathogens, which were resistant to antibiotics by producing the most prevalent antibiotic resistance mechanisms in clinical isolates. While the $S$. aureus ATCC $^{\circledR} 700699^{\text {TM }}$ strain produces a PLP-2a responsible for resistance to methicillin (MRSA), the addition of ON-AuN, restored the susceptibility to DOXY (from $>32 \mathrm{mg} / \mathrm{L}$ to $2 \mathrm{mg} / \mathrm{L}$ ) as in susceptible strain $\mathrm{ATCC}^{\circledR} 25923^{\mathrm{TM}}$ (Table 1). Similarly, resistance to amoxicillin and vancomycin due to a modification of the PBP-5 and the acquisition of the transposon Tn1546 respectively, did not modify the susceptibility to DOXY ON-AuNPs $(\mathrm{MIC}=2 \mathrm{mg} / \mathrm{L})$ in strain BM4147 ${ }^{[46]}$. All these data suggest that the MIC of DOXY ON-AuNPs is not affected by the most prevalent resistance mechanisms in Gram positive bacteria.

\section{Activity of DOXY IN-AuNPs and DOXY ON-AuNPs on P. aeruginosa}

$P$. aeruginosa is the most frequently pathogen in health care associated pneumonia infections in Europe ${ }^{[47]}$. As few molecules are active on $P$. aeruginosa strains due to the production of several intrinsic resistance mechanisms, and its capacity to easily acquired mutations and foreign DNA, we assessed the impact of several resistance mechanisms to antibiotics on the activity of DOXY IN-AuNPs and DOXY ON-AuNPs ${ }^{[48]}$.

P. aeruginosa naturally produces an inducible cephalosporinase, AmpC, that may be overexpressed due to mutations in regulatory pathways genes $(\operatorname{dacB}, \operatorname{amp} G)^{[49]}$. Overproduction of AmpC contributes to ceftazidime resistance, an antibiotic belonging to $\beta$ lactams family and usually used in first line of treatment of $P$. aeruginosa infections. As, the prevalence of AmpC mutants is high in clinical stains, we determined the MIC of DOXY INAuN and DOXY ON-AuNPs in previously AmpC overproduction well-characterized clinical strains (Table 3) in comparison with that of ceftazidime. While the DOXY IN-AuNPs was more active (MIC from 4 to $8 \mathrm{mg} / \mathrm{L}$ ) than DOXY (32 mg/L) like in susceptible strain PAO1, 
it remained less active than DOXY ON-AuNPs. In the five clinical strains $(5134,5168,5250$, 5257, and 5268), the MICs of DOXY ON-AuNPs were identical (2 mg/L) and similar to the MIC of the susceptible strain PAO1 (2 mg/L) (Table 2, and 3) indicating that the activity of DOXY ON-AuNPs is not compromised in strains overproducing AmpC. However, P. aeruginosa may acquire additional $\beta$-lactam resistance mechanisms, notably by the production of enzymes hydrolyzing these molecules ( $\beta$-lactamases) including Extended Spectrum $\beta$-lactamases (ESBL), and carbapenemases. ESBL (Ambler class A $\beta$-lactamases) and carbapenemases (Ambler class B, metallo- $\beta$-lactamases) have been largely reported in $P$. aeruginosa and have worldwide diffused ${ }^{[50]}$.These enzymes contribute to the emergence of Multi-Drug Resistance strains (MDR), and eXtensively Drug Resistant strains (XDR) ${ }^{[51]}$. Whereas the strains were highly resistant to ceftazidime (MIC from 16 to $>64 \mathrm{mg} / \mathrm{L}$ ) and/or imipenem (MIC from 2 to $>64 \mathrm{mg} / \mathrm{L}$ ), the last therapeutic option in $\beta$-lactams, the MICs of DOXY ON-AuNPs were not modified in strains producing ESBL (VEB-1a, SHV-2a, GES-1, and PER-1) or carbapenemases (VIM-2, IMP-13, IMP-15, and NDM-1). All these data show that DOXY ON-AuNPs is stable and is not affected (from 0.5 to $2 \mathrm{mg} / \mathrm{L}$ ) by the major antibiotic resistance mechanisms identified in $P$. aeruginosa clinical strains. These promising results suggest that further studies with AuNPs combined with antibiotics are an interesting approach to challenge antibiotic resistance.

\section{Hypothetical mechanisms for antimicrobial activity of DOXY gold nanoparticles :}

There are many reports on the mechanism of antimicrobial activity of metallic nanoparticles. Unfortunately, the exact mechanism by which nanoparticle inhibits the growth of organism has not been well expounded. It was described by literature ${ }^{[3]}$, that gold nanoparticles interact with the outer membrane of the bacteria through porin channels, and then accumulate on the membrane bilayer matrix, thanks their interaction with lipopolysaccharide and protein ${ }^{[52]}$ damaging the membrane integrity. This behavior could explain the low antibacterial activity 
of gold nanoparticles. Although the mechanism behind the activity of DOXY hybrid nanoconjugate are not yet fully clarified, we suggest that the antibacterial activity of DOXY ON-AuNPs is more better than, DOXY IN-AuNPs and DOXY-AuNPs, compared to DOXY free as control. We believe that after conjugation of DOXY onto AuNPs, by EDC/NHS through PEG-COOH chains, DOXY was protonated and migrate through the PEG chains, assuming a favorite steric conformation to diffuse more freely in the cytoplasm as DOXY molecule charged positively, blocking the binding of aminoacyl-tRNA to the mRNAribosome complex (scheme 4).

The mechanism of enhanced antibacterial activity and advantages of DOXY reduced gold nanoparticles (DOXY-AuNPs) (scheme 5 A) can be explained as follows: DOXY reacts with the outer peptidogylcan layer of Gram-positive bacteria thereby increasing the membrane's permeability, generation of reactive oxygen species (ROS) with oxidative deterioration to cell content. Subsequently, uptake of ions derived from nanoparticles, ATP production, and inhibition of DNA replication ${ }^{[52]}$. Therefore, the combined action of DOXY and Au nanoparticles leads to enhanced antibacterial activity due to relase as DOXY-Au complex negatively charged.

Contrarily, in the formulation DOXY IN-AuNPs, DOXY chelate Au(III) to form a complex before the staking process of PEG diacid chains; in this configuration, DOXY assume a different steric arrangement, in which hydriquinone and chetone groups in the ring B-C chelate $\mathrm{Au}$ ions before reduction with $\mathrm{NaBH}_{4}$ to form AuNPs. In this formulation, DOXY was released in the cytoplasm as DOXY-Au complex through migration in the PEG chains with evident variation in driven force and electrolytic condition (scheme 5B).

Table 1. Susceptibilities of Gram positive bacteria. 


\begin{tabular}{lccccc}
\hline \multicolumn{7}{c}{ MIC (mg/L) } \\
\hline Species & \multicolumn{2}{c}{ Staphylococcus aureus } & $\begin{array}{c}\text { Enterococcus } \\
\text { faecalis }\end{array}$ & \multicolumn{2}{c}{ Enterococcus faecium } \\
Name of reference strains & $\begin{array}{c}\text { ATCC } \\
\text { ATC }\end{array}$ & $\begin{array}{c}\text { ATCC } \\
\text { 25923 }\end{array}$ & UCN41 & BM4147 $^{\mathrm{TM}}$ & ATCC $^{\circledR}$ \\
\hline DOXY & 32 & $>32$ & $>32$ & 32 & 32 \\
DOXY NP-AuNPs & 32 & 32 & 32 & 32 & 32 \\
DOXY IN-AuNPs & 8 & 4 & 4 & 4 & 4 \\
DOXY ON-AuNPs & 1 & 2 & 2 & 2 & 2 \\
Amoxicillin & 1 & 8 & 1 & 8 & 1 \\
\hline
\end{tabular}

Table 2. Susceptibilities of Gram negative bacteria.

\begin{tabular}{|c|c|c|c|c|}
\hline \multirow{3}{*}{$\begin{array}{l}\text { Species } \\
\text { Name of reference strains }\end{array}$} & \multicolumn{4}{|c|}{$M I C(m g / L)$} \\
\hline & & $\begin{array}{c}\text { Klebsiella } \\
\text { pneumoniae }\end{array}$ & $\begin{array}{c}\text { Pseudomonas } \\
\text { aeruginosa }\end{array}$ & $\begin{array}{l}\text { Acinetobacter } \\
\text { baumannii }\end{array}$ \\
\hline & ATCC $^{\circledR} 25922^{\text {TM }}$ & ATCC $^{\circledR} 700603^{\mathrm{TM}}$ & PAO1 & CIP7010 \\
\hline DOXY & 2 & 32 & 32 & 16 \\
\hline DOXY NP-AuNPs & $>32$ & $>32$ & $>32$ & 32 \\
\hline DOXY IN-AuNPs & 8 & 4 & 8 & 4 \\
\hline DOXY ON-AuNPs & 2 & 2 & 2 & 2 \\
\hline Amoxicillin & 0.12 & $>8$ & $>256^{\mathrm{a}}$ & $>256^{\mathrm{a}}$ \\
\hline Ceftazidime & $<0.12$ & 0.12 & 2 & 2 \\
\hline
\end{tabular}

${ }^{a}$ Bacteria intrinsically resistant to amoxicillin. 
WILEY-VCH

Table 3. Susceptibilities of $P$. aeruginosa clinical strains producing various $\beta$-lactamases.

\begin{tabular}{|c|c|c|c|c|c|c|c|c|c|c|c|c|c|c|c|}
\hline \multicolumn{16}{|c|}{$\mathrm{MIC}(\mathrm{mg} / \mathrm{L})$} \\
\hline $\begin{array}{l}\text { Name of clinical } \\
\text { strain }\end{array}$ & 5134 & 5168 & 5250 & 5257 & 5268 & 5213 & 5231 & 5242 & 5176 & 5099 & 4925 & 5190 & 5225 & 5264 & 5269 \\
\hline \multirow{2}{*}{$\begin{array}{l}\text { Resistance } \\
\text { mechanism }\end{array}$} & \multirow{2}{*}{\multicolumn{5}{|c|}{$\begin{array}{l}\text { Strains overproducing the chromosomal } \\
\text { cephalosporinase AmpC }\end{array}$}} & \multicolumn{6}{|c|}{ Strains producing a metallo- $\beta$-lactamase, carbapenemases } & \multicolumn{4}{|c|}{ Strains producing an $\mathrm{ESBL}^{\mathrm{a}}$} \\
\hline & & & & & & & VIM-2 & & IMP-13 & IMP-15 & NDM-1 & VEB-1a & SHV-2a & GES-1 & PER-1 \\
\hline DOXY & 32 & 32 & 32 & 32 & 32 & $>32$ & 32 & 32 & 32 & 32 & 32 & 32 & 32 & $>32$ & 32 \\
\hline DOXY IN-AuNPs & 8 & 8 & 8 & 8 & 4 & 8 & 8 & 8 & 4 & 32 & 8 & 32 & 8 & 8 & 8 \\
\hline DOXY ON-AuNPs & 2 & 2 & 2 & 2 & 2 & 2 & 2 & 2 & 2 & 0.5 & 2 & 0.5 & 2 & 2 & 2 \\
\hline Ceftazidime & 32 & 4 & 64 & 4 & $>64$ & $>64$ & $>64$ & 16 & $>64$ & 64 & $>64$ & $>64$ & 16 & $>64$ & $>64$ \\
\hline Imipenem & 2 & 2 & 2 & 2 & 2 & $>64$ & $>64$ & 32 & $>64$ & 16 & $>64$ & 4 & $>32$ & 2 & $>64$ \\
\hline
\end{tabular}

${ }^{a}$ ESBL, Extended Spectrum- $\beta$-lactamase. 


\section{WILEY-VCH}

\section{EXPERIMENTAL SECTION}

\section{Materials}

Tetrachloroauric acid $\left(\mathrm{HAuCl}_{4}\right)$, sodium borohydride $\left(\mathrm{NaBH}_{4}\right)$, N-hydroxysuccinimide (NHS), 1-(3-dimethylaminopropyl)-N'-ethylcarbodiimidehydrochloride (EDC), PEG-600 diacid, doxycycline hydrochloride (DOXY), bacterial culture media, was purchased from Sigma-Aldrich (St Louis, MO, USA). All solvents were reagentgrade and used without any further purification. All bacteria were provided by Laboratoire de Bactériologie, Centre National de Référence (CNR) (France). Experiments were carried out at room temperature if not specified otherwise.

\section{Preparation of Nanoparticles}

Three strategies of synthesis were tested to conjugate DOXY to AuNPs:

\section{Doxycycline reducing and formation of DOXY-AuNPs}

DOXY-AuNPs were synthesized by mixing $20 \mathrm{~mL}$ of $\mathrm{HAuCl}_{4}$ solution $\left(8.63 \times 10^{-4} \mathrm{M}\right)$ with $4 \mathrm{~mL}$ of DOXY $(1 \mathrm{mg} / \mathrm{mL})$ followed by the addition of $3 \mathrm{~mL} \mathrm{NaOH}(1 \mathrm{mM})$. After 15min of reaction, the as-prepared DOXY-AuNPs solution was centrifuged at $15.000 \mathrm{rpm}$ for $30 \mathrm{~min}$ for three times to remove the excess of DOXY and then the supernatant was discarded, and the residue was redispersed in an equivalent amount of water. This was repeated twice. 


\section{WILEY-VCH}

\section{Doxycycline loading into AuPEG and formation of DOXY IN-AuNPS}

Synthesis of DOXY IN-AuNPs colloids included three main steps: (Scheme 1C). $20 \mathrm{~mL} \mathrm{HAuCl}{ }_{4}$ solution $\left(8.63 \times 10^{-4} \mathrm{M}\right)$ was mixed to DOXY (200 $\mu \mathrm{L}, 1 \mathrm{mg} / \mathrm{mL}$ in water) and aged for $10 \mathrm{~min}$. After $10 \mathrm{~min}, 1 \mathrm{~mL}$ of dicarboxylic PEG was added. Finally, $300 \mu \mathrm{L}$ of aqueous $0.01 \mathrm{M} \mathrm{NaBH}_{4} \mathrm{Was}$ added at once. After $15 \mathrm{~min}$ of reaction, the as-prepared DOXY-AuNPs solution was centrifuged at $15.000 \mathrm{rpm}$ for $30 \mathrm{~min}$ for three times to remove the excess of DOXY and PEG and then the supernatant was discarded, and the residue was redispersed in an equivalent amount of water. This was repeated twice.

\section{Doxycycline loading onto AUPEG and formation of DOXY ON-AUNPS}

\section{Synthesis of pegylated-gold nanoparticles (PEG-AuNPs)}

Synthesis of AuPEG Colloids of COOH-terminated PEG-coated AuNPs (PEG-AuNPs) were prepared according to previously described procedure ${ }^{[20]}$ [19] [53] [31]. Briefly, $20 \mathrm{~mL}$ of chloroauric acid $\left(\mathrm{HAuCl}_{4}\right)$ aqueous solution $\left(8.63 \times 10^{-4} \mathrm{M}\right)$ was added to $0.25 \mathrm{~mL}$ of dicarboxylic PEG and mixed by magnetic stirring for 10 minutes at room temperature. To this solution, $6 \mathrm{~mL}$ of aqueous $0.01 \mathrm{M} \mathrm{NaBH}_{4}$ was added at once. The color of the dispersion indeed instantly changed from yellow to red when sodium borohydride was added to a solution of gold precursor in the presence of PEG-diacid polymer, confirming the formation of AuPEG in the solution. The as-prepared PEGAu NP solution was purified by centrifugation to remove excess of non-conjugated dicarboxylic PEG. Centrifugation was carried out at 15,000 rpm for 30 minutes for three times in order to remove the excess of PEG and then the supernatant was discarded. The residue was redispersed in an equivalent amount of water. This was repeated twice. Conjugation of DOXY to PEG-AuNPs surface was carried out as from previous published work ${ }^{[19]}$ using a carbodiimide-based conjugation of the 
carboxylic-terminated polymer. Briefly, $50 \mu \mathrm{L}$ of EDC/NHS (40/10 mg ratio) aqueous solution was added to $5 \mathrm{~mL}$ of PEG-AuNPs. After 2 hours, DOXY (50 $\mu \mathrm{L}$, $1 \mathrm{mg} / \mathrm{mL}$ ) was added and aged for 2 hours. The reaction mixture was then centrifuged three times and

redispersed in water to remove any unbound DOXY. The encapsulation efficiency (percentage of DOXY bound to nanoparticles) was calculated as the difference between the initial drug content and the amount of free DOXY in the filtrate after separation of the nanoparticles by ultrafiltration (Ultrafree MC centrifugal filter units, 30,000 NMWL; Merck Millipore, Darmstadt, Germany). The reaction efficiency was equal to 85\%.

\section{Physico-chemical characterization}

All the measurements were performed in duplicate in order to validate the reproducibility of the synthetic procedure.

UV-Vis absorption spectroscopy: All experiments were performed as previously described ${ }^{[19]}$ in water at AuNPs concentration equal to $10^{-4} \mathrm{M}$.

Transmission Electron microscopy (TEM): All microscopy analysis were realized as previously described ${ }^{[19]}$ [16] $^{\text {. }}$

Raman Spectroscopy: The Raman experiments have been performed on an Xplora spectrometer (Horiba Scientifics-France). The Raman spectra have been recorded using an excitation wavelength of $785 \mathrm{~nm}$ (diode laser) at room temperature. For measurements in solution, a macro-objective with a focal length of $40 \mathrm{~mm}(\mathrm{NA}=$ 0.18) was used in backscattering configuration. The achieved spectral resolution is close to $2 \mathrm{~cm}^{-1}$.

Dynamic light scattering (DLS): The size measurements were performed using a Zetasizer Nano ZS (Malvern Instruments, Malvern, UK) equipped with a He-Ne laser $\left(633 \mathrm{~nm}\right.$, fixed scattering angle of $\left.173^{\circ}\right)$ at room temperature. 


\section{WILEY-VCH}

Zeta potential measurements: All measurements were carried out as previously described ${ }^{[16]}$.

\section{Stability of Doxy gold nanoparticles (DOXY-AuNPs, DOXY IN-AuNPs, DOXY ON-AuNPs) as a function of pH.}

For stability studies, all nanoparticles were dispersed in bacterial culture media (0.1 M; pH 8), and absorption spectra collected over 3 months (Figure S1 Supporting

\section{Informations).}

DOXY loading efficiency: The amount of the antibiotic incorporated into PEG-AuNPs was measured by UV-Vis absorption spectroscopy. Absorption at 350-275 nm was used to extrapolate DOXY concentrations based on a calibration curve (Figure S2 in the Supporting Information). Because the AuNPs spectrum could interfere with DOXY detection, the DOXY loading efficiency was calculated as follows (Equation 1):

$$
\text { DOXY loading efficiency }(\%)=\frac{C_{1}-C_{2}}{C_{1}} \times 100 \text { Equation } 1
$$

Where $C_{1}$ is the initial drug content and $C_{2}$ is the amount of free doxorubicin in the filtrate ${ }^{[16]}$.

\section{Antimicrobial Assay}

\section{Bacterial strains}

Enterococcus faecalis UCN41, Enterococcus faecium BM4147 and ATCC ${ }^{\circledR} 19434 \mathrm{~T}^{\mathrm{TM}}$, Klebsiella pneumoniae ATCC $^{\circledR} 700603^{\mathrm{TM}}$, Escherichia coli $\mathrm{ATCC}^{\circledR} 25922^{\mathrm{TM}}$, Acinetobacter baumannii CIP7010, and Pseudomonas aeuginosa PAO1 strains were used as reference strains ${ }^{[46,54]}$. P. aeruginosa clinical isolates were isolated from blood culture and tracheal aspirates at the teaching hospital of Besançon, France (CHRU Jean Minjoz). Well-characterized P. aeruginosa strains from the collection of the French National Reference Centre (NRC) for Antibiotic Resistance were also included in the study to evaluate the activity of the synthetized compounds derivative 


\section{WILEY-VCH}

from DOXY. The collection included 15 well-characterized resistant $P$. aeruginosa strains, of which 6 were carbapenems producers including 3 VIM-2, one IMP-13, one IMP-15, and one NDM-1, 4 Extended-Spectrum B-Lactamases (ESBL) producers including (GES-1, PER-1, SHV-2a, and VEB-1a), and 5 AmpC overproducers.

\section{Susceptibility testing}

The minimum inhibitory concentrations (MICs) of the selected strains were determined by microdilution method in Mueller Hinton Broth (MHB, Becton Dickinson, Le Pont de Claix, France) containing adjusted concentrations of $\mathrm{Ca}^{2+}$ (from 20 to $25 \mathrm{mg} / \mathrm{L}$ ) and $\mathrm{Mg}^{2+}$ (from 10 to $12.5 \mathrm{mg} / \mathrm{L}$ ) according to Clinical and Laboratories

Standards Institute recommendations ${ }^{[55]}$. Briefly, from fresh bacterial cultures, microplates were inoculated with $10^{5} \mathrm{CFU} / \mathrm{mL}$ in $\mathrm{MHB}$ containing serial dilutions of molecules and incubated at $35^{\circ} \mathrm{C}$ for $18 \mathrm{~h}$. MICs of the molecules tested were compared to antibiotics usually used as reference according to the species. MICs were defined as the lowest concentration of antibiotic that completely inhibits visible growth after $24 \mathrm{~h}$ of incubation at $35^{\circ} \mathrm{C}$. MICs of indicated antibiotics and molecules were determined in triplicate. 


\section{WILEY-VCH}

\section{CONCLUSION}

In this study, we described a new approach to synthetize new antibacterial nanotherapeutics based on stable DOXY-gold nanoparticles. Chemical physics characterizations were extensively achieved and fully elucidated the formation mechanism of the nanostructure and the DOXY conformational changes associated with such processes. Infact, the amine group of DOXY acts as both a reducing and stabilizing agent and therefore the antibacterial activity of DOXY is preserved due to the presence of the free $\beta$ lactam ring being available on the surface of the nanoparticles. The capping agents aren't needed on the surface of nanoparticles due to block potential adsorption surface sites. However, we have shown that PEG played a key role in the loading of DOXY around the particle, which culminated in an increased bactericidal activity towards major human pathogens (Staphylococcus aureus, Escherichia coli, Klebsiella pneumoniae, Pseudomonas aeruginosa, and Acinetobacter baumannii). Thus, DOXY -loaded nanoparticles could be used efficiently for antibacterial therapy, against a variety number of bacterial species. Given these bestquality results, this antibiotic system based on doxycicline constitutes a real promise as a therapeutic entity in disease treatment. Further studies are still envisaged, focused on no-cycline-cycline hybrid antibiotic nanoparticles in order to improve the selectivity and efficacy of the antibacterial system.

\section{ASSOCIATED CONTENT}

Supporting Information. Supplementary figures, schemes and tables are provided. This material is available free of charge via the Internet at http://.....

\section{Corresponding Author}




\section{ACKNOWLEDGMENT}

This work was supported by project from the Centre National of Recherche (CNRS) and Univ-Paris13

\section{Reference :}

[1] M. Exner, S. Bhattacharya, B. Christiansen, J. Gebel, P. Goroncy-Bermes, P. Hartemann, P. Heeg, C. Ilschner, A. Kramer, E. Larson, W. Merkens, M. Mielke, P. Oltmanns, B. Ross, M. Rotter, R. M. Schmithausen, H.-G. Sonntag, M. Trautmann, GMS Hygiene and Infection Control 2017, 12 , Doc05.

[2] M. J. Silvero C, D. M. Rocca, E. A. de la Villarmois, K. Fournier, A. E. Lanterna, M. F. Pérez, M. C. Becerra, J. C. Scaiano, ACS Omega 2018, 3, 1220-1230.

[3] A. Rai, A. Prabhune, C. C. Perry, Journal of Materials Chemistry 2010, 20, 6789-6798.

[4] R. Misra, S. K. Sahoo, Methods Enzymol 2012, 509, 61-85.

[5] H. F. O. Silva, K. M. G. Lima, M. B. Cardoso, J. F. A. Oliveira, M. C. N. Melo, C. Sant'Anna, M. Eugênio, L. H. S. Gasparotto, RSC Advances 2015, 5, 66886-66893.

[6] N. F. Cover, S. Lai-Yuen, A. K. Parsons, A. Kumar, Int J Nanomedicine 2012, 7, 2411-2419.

[7] P. Liu, H. Wang, J. K. Hiltunen, Z. Chen, J. Shen, Particle \& Particle Systems Characterization 2015, 32, 749-755.

[8] D. Cheng, M. Yu, F. Fu, W. Han, G. Li, J. Xie, Y. Song, M. T. Swihart, E. Song, Analytical Chemistry 2016, 88, 820-825.

[9] J. Kreuter, Infection 1991, 19, S224-S228.

[10] H. Pinto-Alphandary, A. Andremont, P. Couvreur, International journal of antimicrobial agents 2000, 13, 155-168.

[11] H. Gu, P. L. Ho, E. Tong, L. Wang, B. Xu, Nano Letters 2003, 3, 1261-1263.

[12] B. Saha, J. Bhattacharya, A. Mukherjee, A. Ghosh, C. Santra, A. K. Dasgupta, P. Karmakar, Nanoscale Research Letters 2007, 2, 614.

[13] H. Deng, D. McShan, Y. Zhang, S. S. Sinha, Z. Arslan, P. C. Ray, H. Yu, Environmental science \& technology 2016, 50, 8840-8848.

[14] N. Joshi, D. Q. Miller, Arch Intern Med 1997, 157, 1421-1428.

[15] B. A. Cunha, P. Domenico, C. B. Cunha, Clin Microbiol Infect 2000, 6, 270-273. 


\section{WILEY-VCH}

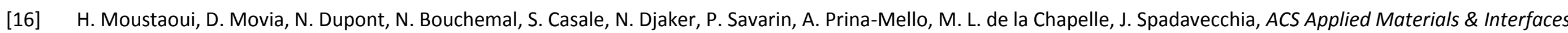
2016, 8, 19946-19957.

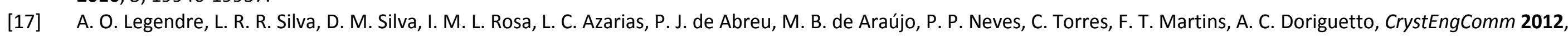
$14,2532-2540$.

[18] M. Zilberman, J. J. Elsner, Journal of Controlled Release 2008, 130, 202-215.

[19] J. Spadavecchia, D. Movia, C. Moore, C. M. Maguire, H. Moustaoui, S. Casale, Y. Volkov, A. Prina-Mello, in Int J Nanomedicine, Vol. 11,2016, pp. 791-822.

[20] J. Spadavecchia, R. Perumal, A. Barras, J. Lyskawa, P. Woisel, W. Laure, C. M. Pradier, R. Boukherroub, S. Szunerits, The Analyst 2014, 139, 157-164.

[21] A. Fakhri, S. Tahami, M. Naji, Journal of Photochemistry and Photobiology B: Biology 2017, 169, 21-26.

[22] R. Jagannathan, P. Poddar, A. Prabhune, The Journal of Physical Chemistry C 2007, 111, 6933-6938.

[23] X. Peng, J. Wickham, A. P. Alivisatos, Journal of the American Chemical Society 1998, 120, 5343-5344.

[24] S. S. Shankar, S. Bhargava, M. Sastry, Journal of nanoscience and nanotechnology 2005, 5, 1721-1727.

[25] S. K. Nune, N. Chanda, R. Shukla, K. Katti, R. R. Kulkarni, S. Thilakavathi, S. Mekapothula, R. Kannan, K. V. Katti, Journal of materials chemistry 2009, $19,2912-2920$.

[26] M. Gwendolyn, M. Hanane, H. M. Ben, D. Nadia, C. M. Lamy, S. Jolanda, Particle \& Particle Systems Characterization 2018, $35,1700299$.

[27] L. Hui, J. Peng, L. Zhonghu, L. Xiaowu, D. Nadia, S. Jolanda, Particle \& Particle Systems Characterization, 0, 1800082.

[28] B. A. Cunha, C. M. Sibley, A. M. Ristuccia, Ther Drug Monit 1982, 4, 115-135.

[29] I. Chopra, M. Roberts, Microbiol Mol Biol Rev 2001, 65, 232-260.

[30] S. Link, M. A. El-Sayed, The Journal of Physical Chemistry B 1999, 103, 8410-8426.

[31] J. Spadavecchia, E. Apchain, M. Alberic, E. Fontan, I. Reiche, Angewandte Chemie (International ed. in English) 2014, 53, 8363-8366.

[32] P. K. Jain, K. S. Lee, I. H. El-Sayed, M. A. El-Sayed, The Journal of Physical Chemistry B 2006, 110, 7238-7248.

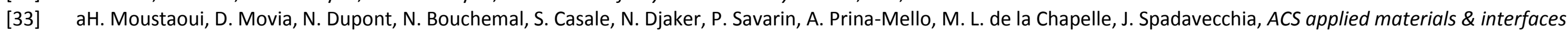
2016, 8, 19946-19957; bJ. Politi, L. De Stefano, S. Longobardi, P. Giardina, I. Rea, C. Methivier, C. M. Pradier, S. Casale, J. Spadavecchia, Colloids and surfaces. B, Biointerfaces 2015, 136, 214-221; cJ. Spadavecchia, D. Movia, C. Moore, C. M. Maguire, H. Moustaoui, S. Casale, Y. Volkov, A. Prina-Mello, International journal of nanomedicine 2016, 11, 791-822.

[34] G. Marguerit, H. Moustaoui, M. B. Haddada, N. Djaker, M. L. Chapelle, J. Spadavecchia, Particle \& Particle Systems Characterization 2018, 35, 1700299.

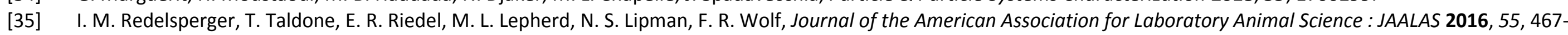
474.

[36] R. K. Franklin, S. A. Marcus, A. M. Talaat, B. K. KuKanich, R. Sullivan, L. A. Krugner-Higby, T. D. Heath, Drug Metabolism and Disposition 2015, $43,1236-1245$.

[37] A. Omri, M. Ravaoarinoro, International journal of antimicrobial agents 1996, 7, 9-14.

[38] G. Budai, G. Maróti, R. Dekker, D. Huisman, L. Kroon, Journal of Scheduling 2010, 13, 281-297.

[39] I. V. Zhigaltsev, N. Maurer, K. Edwards, G. Karlsson, P. R. Cullis, Journal of Controlled Release 2006, 110, 378-386.

[40] W. Tu, X. Xu, L. Peng, X. Zhong, W. Zhang, M. M. Soundarapandian, C. Balel, M. Wang, N. Jia, W. Zhang, F. Lew, S. L. Chan, Y. Chen, Y. Lu, Cell 2010, 140, 222-234.

[41] I. Capek, Advances in colloid and interface science 2017.

[42] I. Chopra, M. Roberts, Microbiology and Molecular Biology Reviews 2001, 65, 232-260.

[43] D. E. Brodersen, W. M. Clemons, A. P. Carter, R. J. Morgan-Warren, B. T. Wimberly, V. Ramakrishnan, Cell 2000, 103, 1143-1154.

[44] C. Marambio-Jones, E. M. V. Hoek, Journal of Nanoparticle Research 2010, 12, 1531-1551. 


\section{WILEY-VCH}

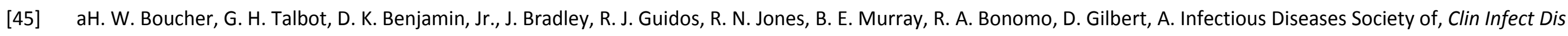
2013, 56, 1685-1694; bD. M. Shlaes, D. Sahm, C. Opiela, B. Spellberg, Antimicrobial Agents and Chemotherapy 2013, 57, $4605-4607$.

[46] T. D. Bugg, G. D. Wright, S. Dutka-Malen, M. Arthur, P. Courvalin, C. T. Walsh, Biochemistry 1991, 30, 10408-10415.

[47] H. S. Sader, D. J. Farrell, R. K. Flamm, R. N. Jones, Int J Antimicrob Agents 2014, 43, 328-334.

[48] P. D. Lister, D. J. Wolter, N. D. Hanson, Clin Microbiol Rev 2009, 22, 582-610.

[49] C. Juan, G. Torrens, M. Gonzalez-Nicolau, A. Oliver, FEMS Microbiol Rev 2017, 41, 781-815.

[50] A. Potron, L. Poirel, P. Nordmann, Int J Antimicrob Agents 2015, 45, 568-585.

[51] A. P. Magiorakos, A. Srinivasan, R. B. Carey, Y. Carmeli, M. E. Falagas, C. G. Giske, S. Harbarth, J. F. Hindler, G. Kahlmeter, B. Olsson-Liljequist, D. L. Paterson, L. B. Rice, J. Stelling, M. J. Struelens, A. Vatopoulos, J. T. Weber, D. L. Monnet, Clin Microbiol Infect 2012, 18, 268-281.

[52] H. Bajaj, S. Acosta Gutierrez, I. Bodrenko, G. Malloci, M. A. Scorciapino, M. Winterhalter, M. Ceccarelli, ACS Nano 2017, 11, 5465-5473.

[53] V. Melani, M. B. Haddada, H. Moustaoui, J. Landoulsi, N. Djaker, M. L. de la Chapelle, J. Spadavecchia, Frontiers in Laboratory Medicine 2017, 1, 114-121.

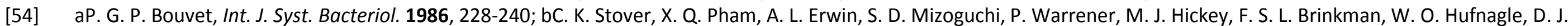
Kowalik, M. Lagrou, R. L. Garber, L. Goltry, E. Tolentino, S. Westbrock-Wadman, Y. Yuan, L. L. Brody, S. N. Coulter, K. R. Folger, A. Kas, K. Larbig, R. Lim, K. Smith, D. Spencer, G. K.-S. Wong, Z. Wu, I. T. Paulsen, J. Reizer, M. H. Saier, R. E. W. Hancock, S. Lory, M. V. Olson, Nature (London) 2000, 406, 959-964.

[55] CLSI, Clinical and Laboratory Standards Institute, Wayne, PA, 2017.

\section{Figures and scheme}




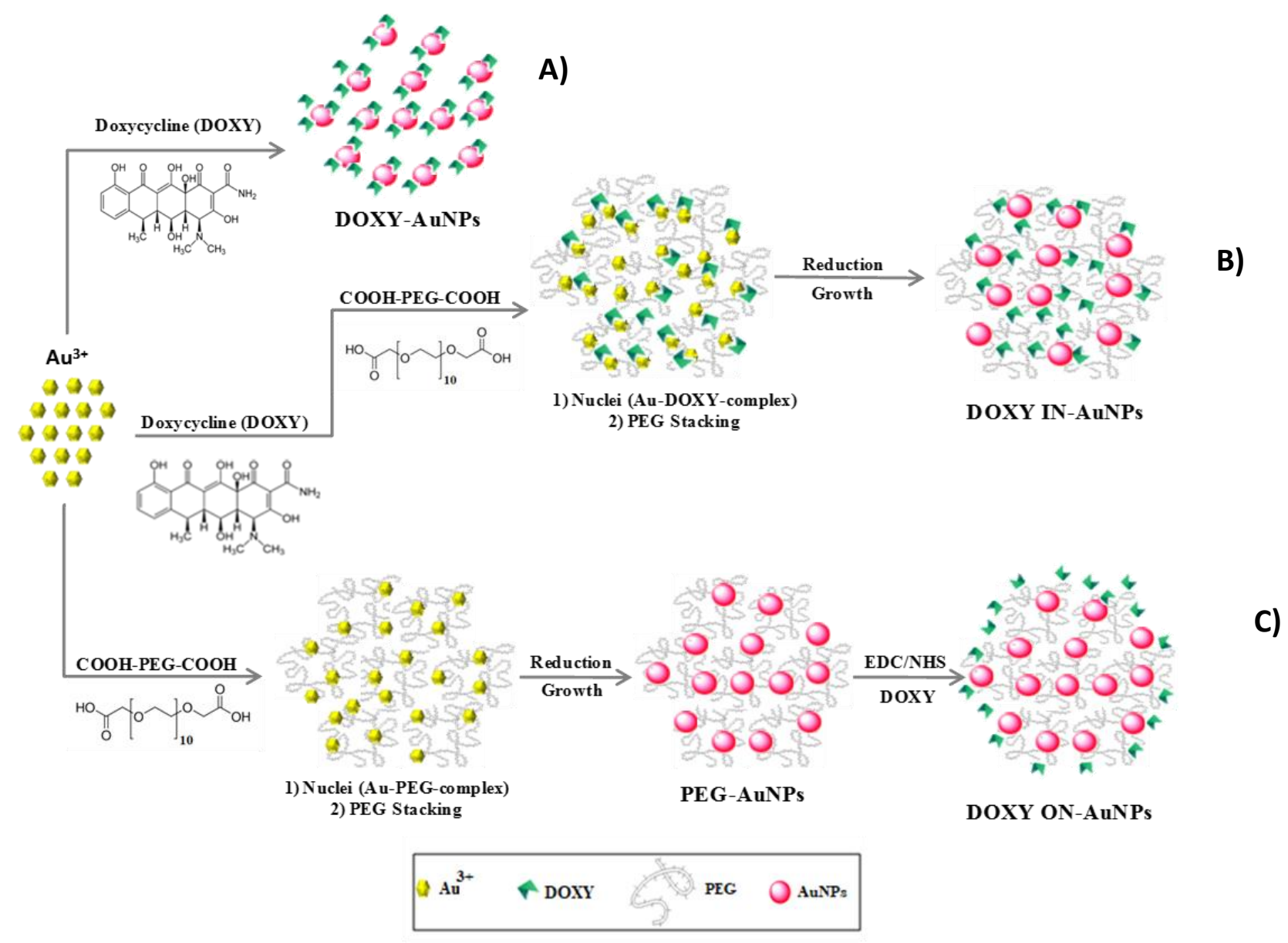

Scheme 1. Schematic representation of two possible mechanisms for the synthesis of DOXY-AuNPs, DOXY IN-AuNPs and DOXY ON-AuNPs. It should be noted that the scheme is not to scale. 


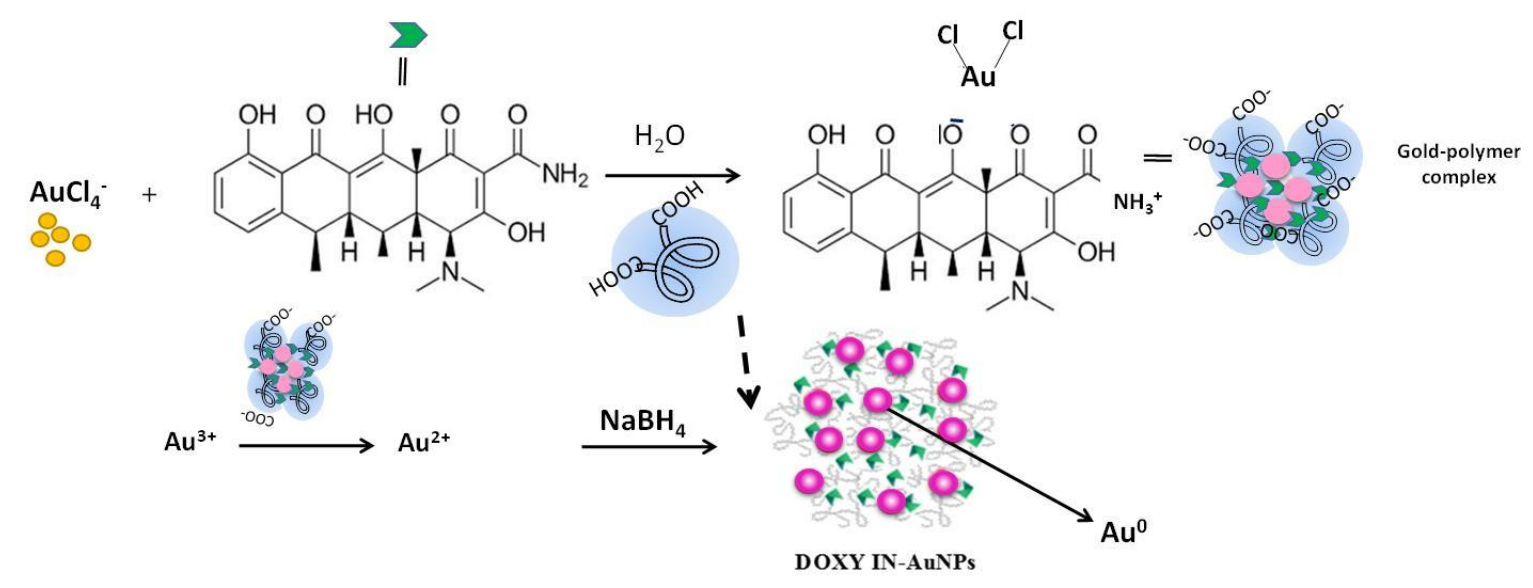

Scheme 2: Schematic of proposed mechanism of $\mathrm{AuCl}_{4}{ }^{-}$reduction and particle formation in the presence of DOXY as surfactant (Please note that drawings are not in scale and are not intended to be representative of the full samples composition). 

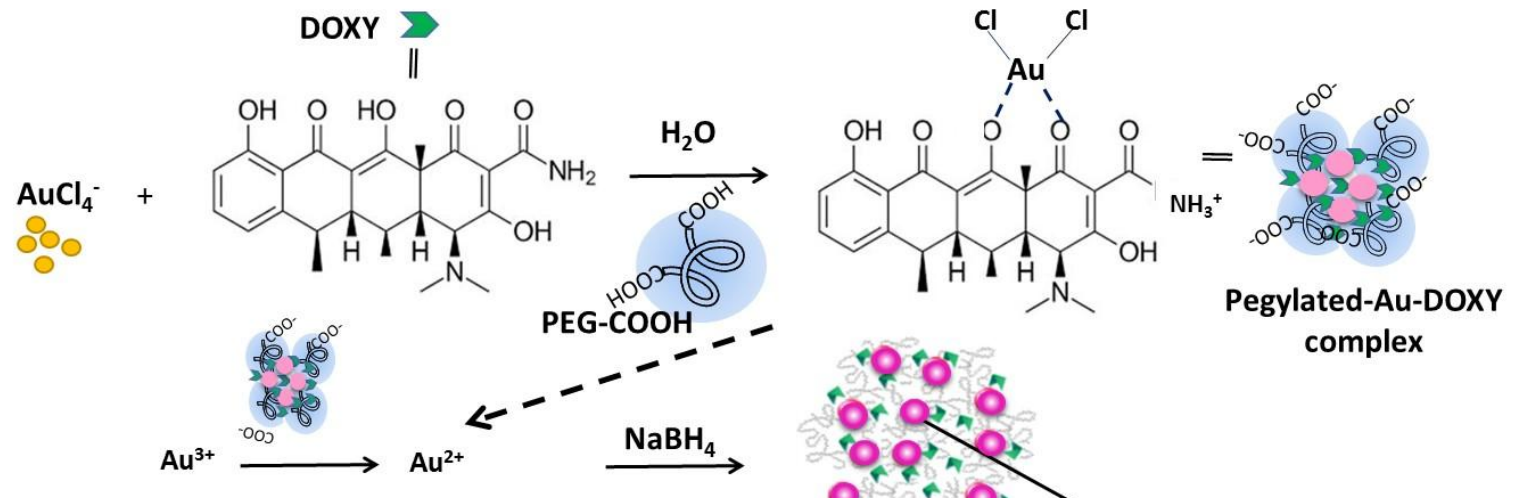

complex

Scheme 3: Schematic of proposed mechanism of $\mathrm{AuCl}_{4}{ }^{-}$reduction and particle formation in the presence of DOXY and PEG-diacid as surfactants (Please note that drawings are not in scale and are not intended to be representative of the full samples composition). 
WILEY-VCH

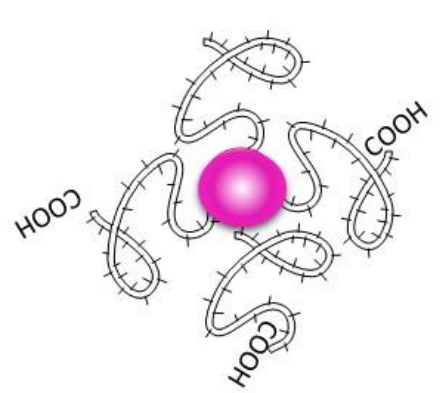

PEG-AuNPs

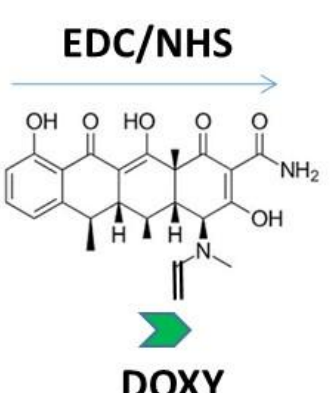

DOXY

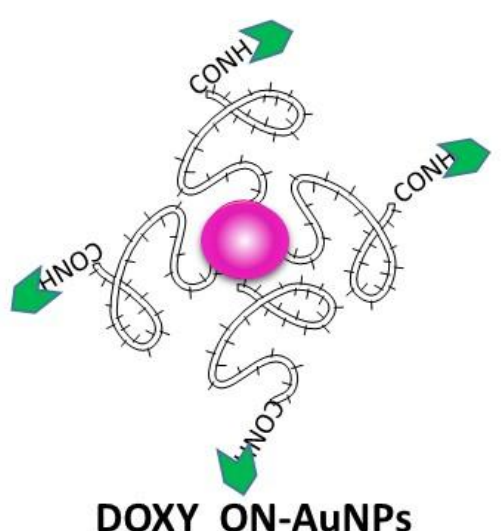

Scheme 4: Representation of Doxycicline conjugation onto PEG-AuNPs by carbodiimide chemistry (Please note that drawings are not in scale and are not intended to be representative of the full samples composition). 

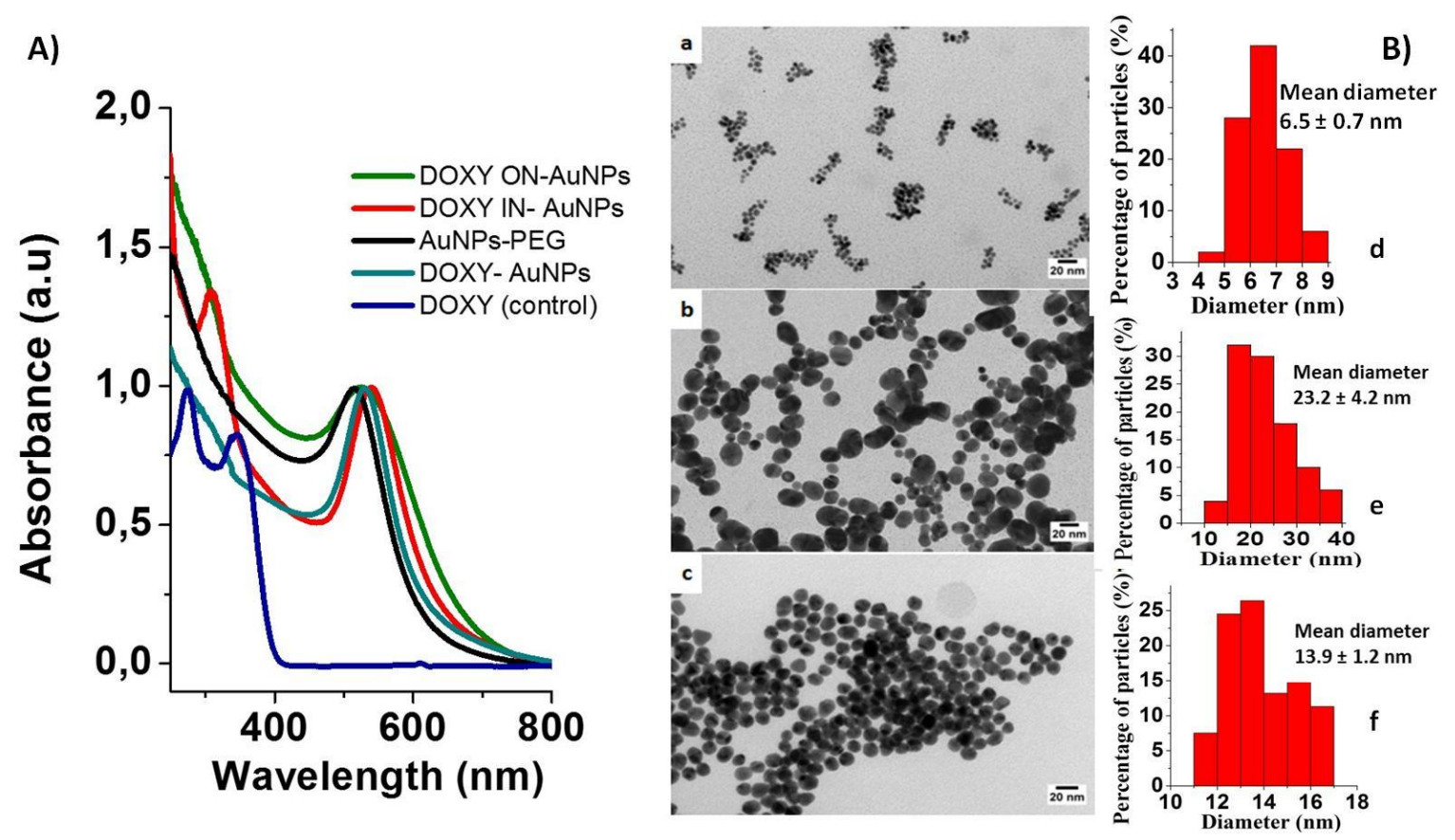

Figure 1. A) UV-Vis spectra of the prepared AuNPs. B) TEM images and size distribution of the prepared DOXY-AuNPs (a,d), DOXY IN-AuNPs (b,e) and DOXY ON-AuNPs (c,f). 


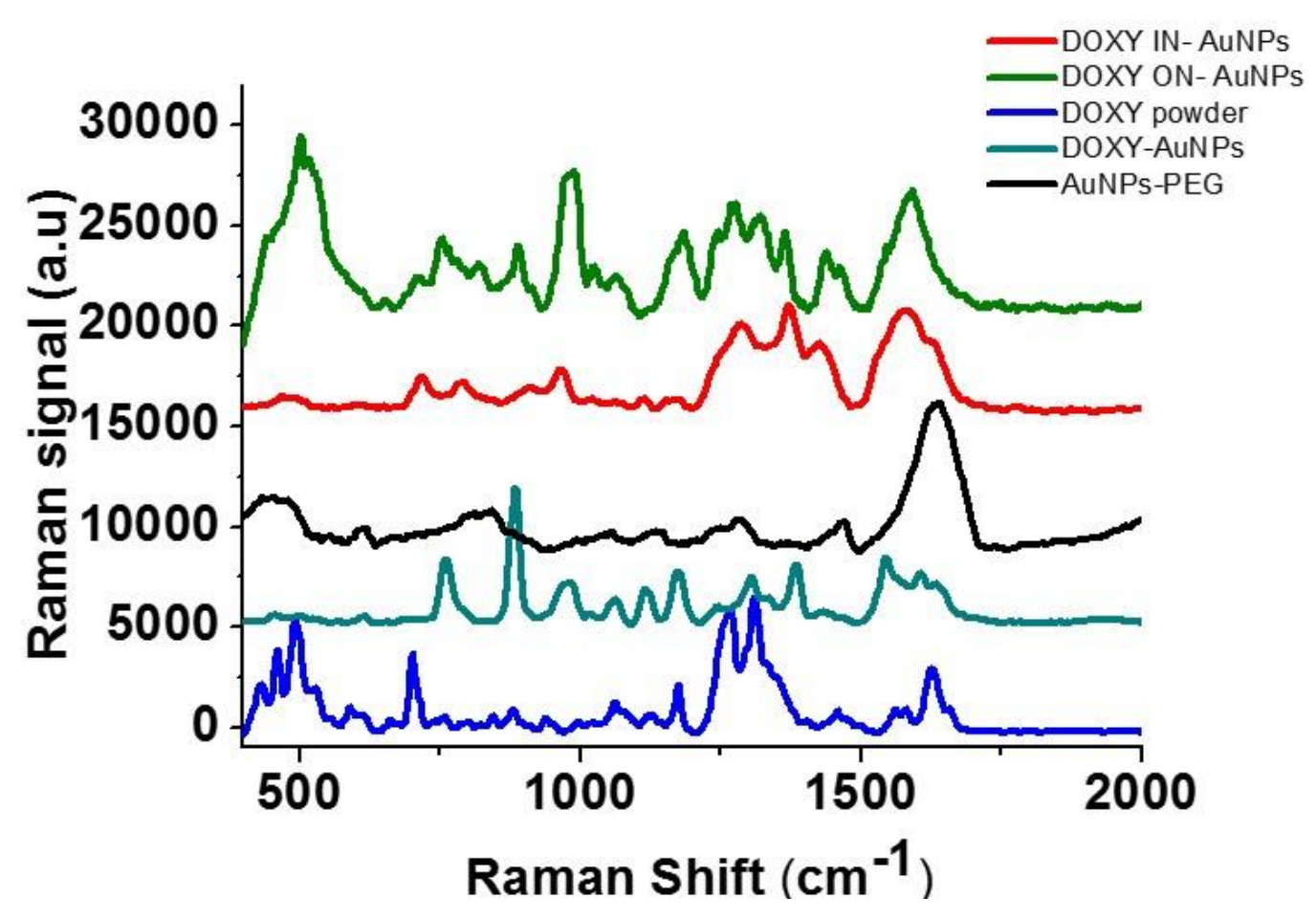

Figure 2. Raman spectra of DOXY-AuNPs, DOXY IN-AuNPs and DOXY ON-AuNPs, DOXY powder and COOH-terminated PEG (PEG-COOH) are also reported for comparison. Experimental conditions: $\lambda \operatorname{exc}=785 \mathrm{~nm}$; laser power $20 \mathrm{~mW}$; $600 \mathrm{~T}$ of $120 \mathrm{~s}$. 

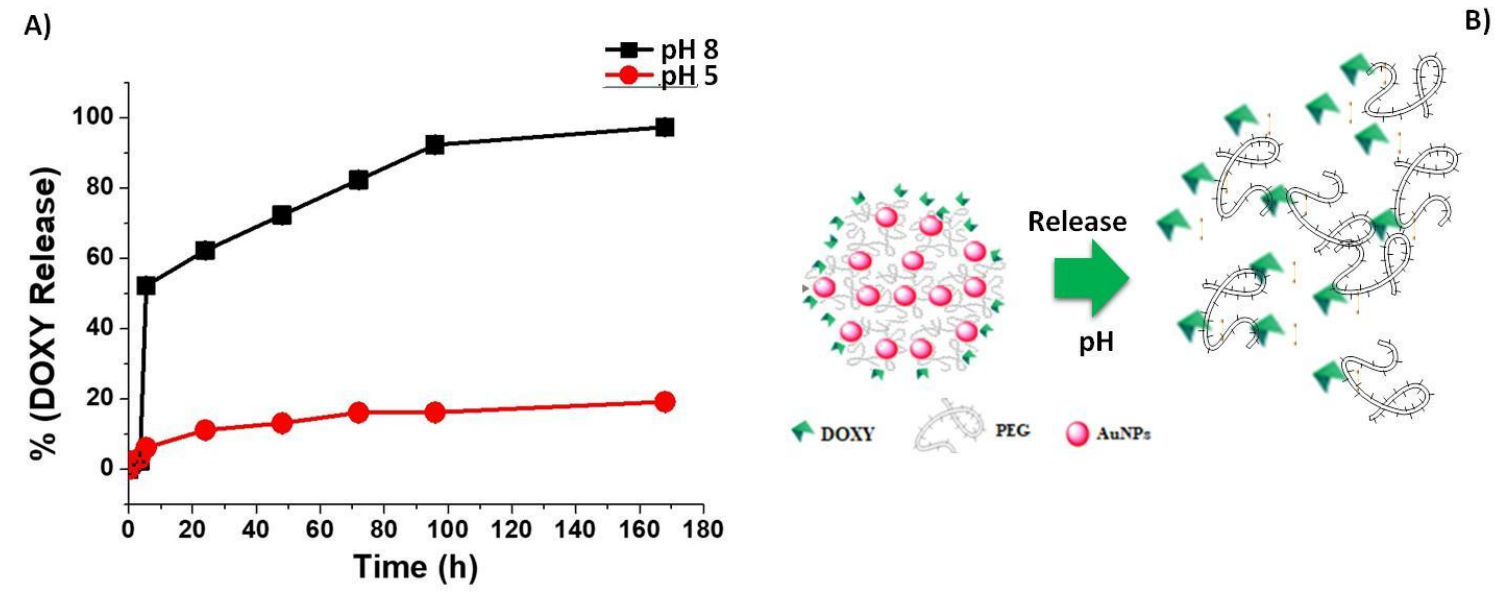

Figure 3: A) Drug release percentage (\%) of DOXY ON AuNPs time in PBS $\left(37^{\circ} \mathrm{C}\right)$ at $\mathrm{pH}=5.0$ or at $\mathrm{pH}=8.0$. B) Schematic diagram of DOXY release under $\mathrm{pH}$ conditions. 
WILEY-VCH

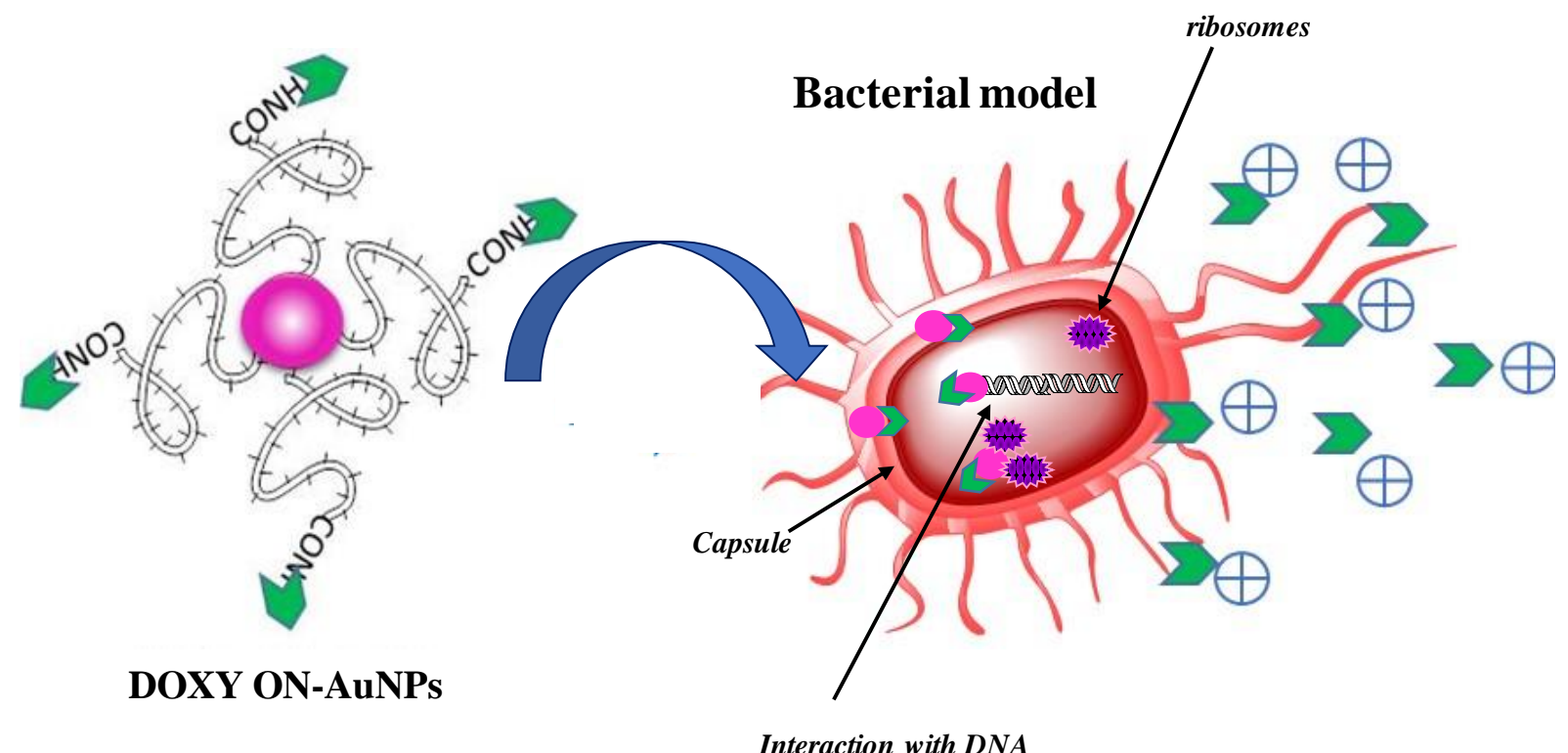

Interaction with DNA

Scheme 4: Scheme summarizing DOXY ON-AuNPs interaction with bacterial cells. (Please note that drawings are not in scale and are not intended to be representative of the full samples composition). 
A)

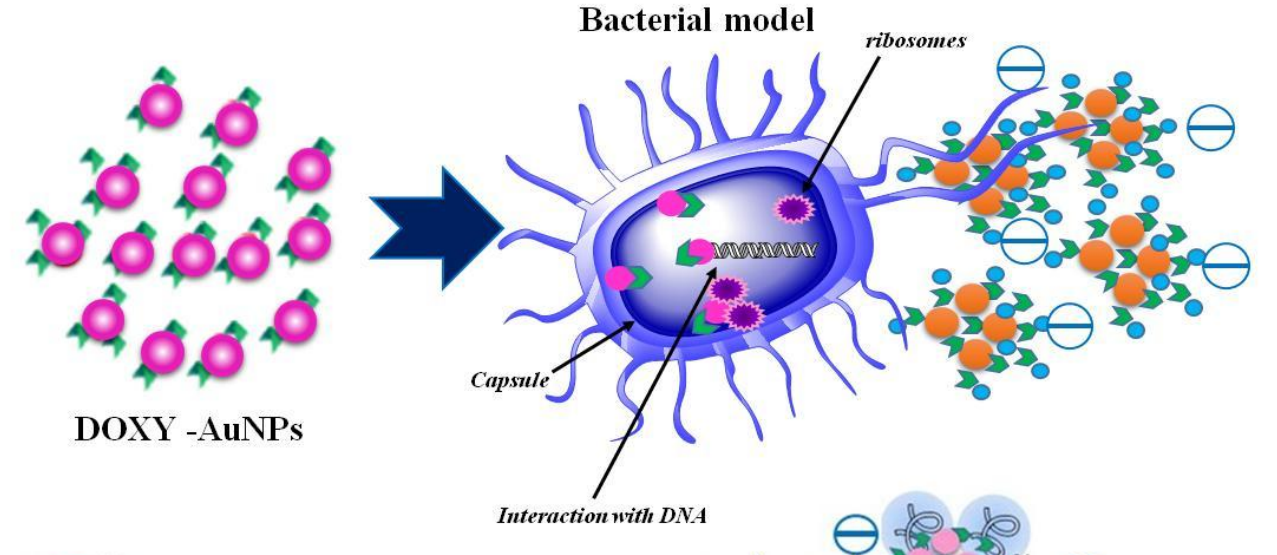

B)

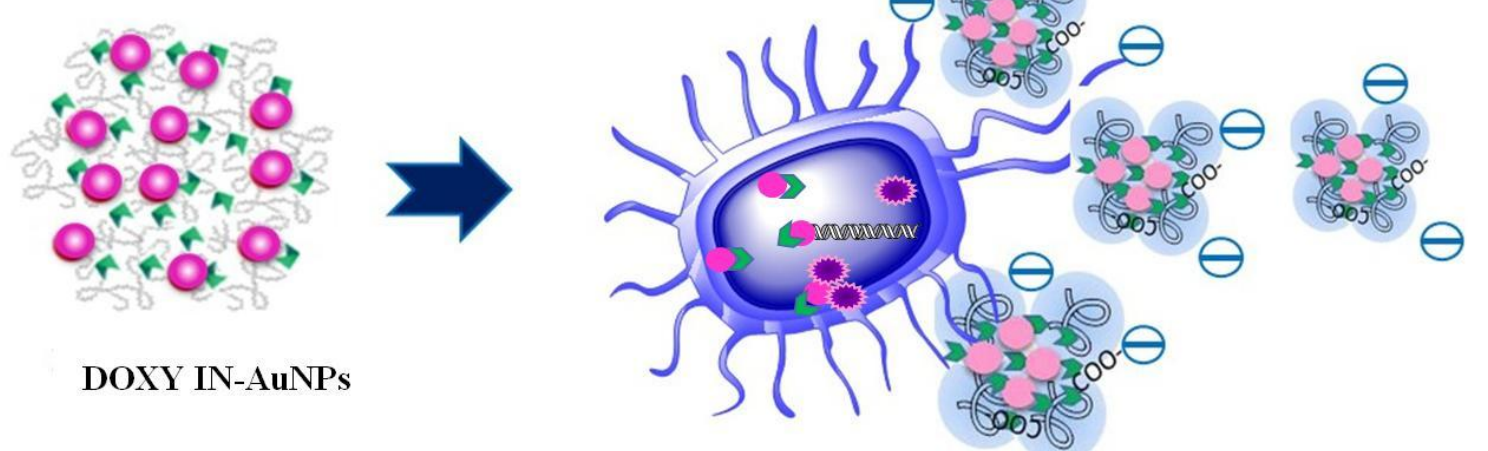

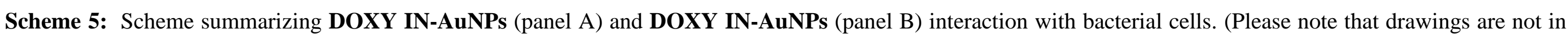
scale and are not intended to be representative of the full samples composition). 


\section{Supporting Information}

Novel synthesis and characterization of doxycycline-loaded gold nanoparticles. The golden doxycycline for antibacterial applications.

Maroua Ben Haddada ${ }^{1}$, Katy Jeannot ${ }^{2}$, Jolanda Spadavecchia ${ }^{1}{ }^{1}$

${ }^{1}$ CNRS, UMR 7244, CSPBAT, Laboratoire de Chimie, Structures et Propriétés de Biomateriaux et d'Agents Therapeutiques Université Paris 13, Sorbonne Paris Cité, Bobigny, France

${ }^{2}$ Laboratoire de Bactériologie, Centre National de Référence (CNR) de la Résistance aux Antibiotiques, Centre Hospitalier Régional Universitaire (CHRU) de Besançon, UMR4269 "Chrono-Environnement", Boulevard Fleming, 25030 Besançon, France. 


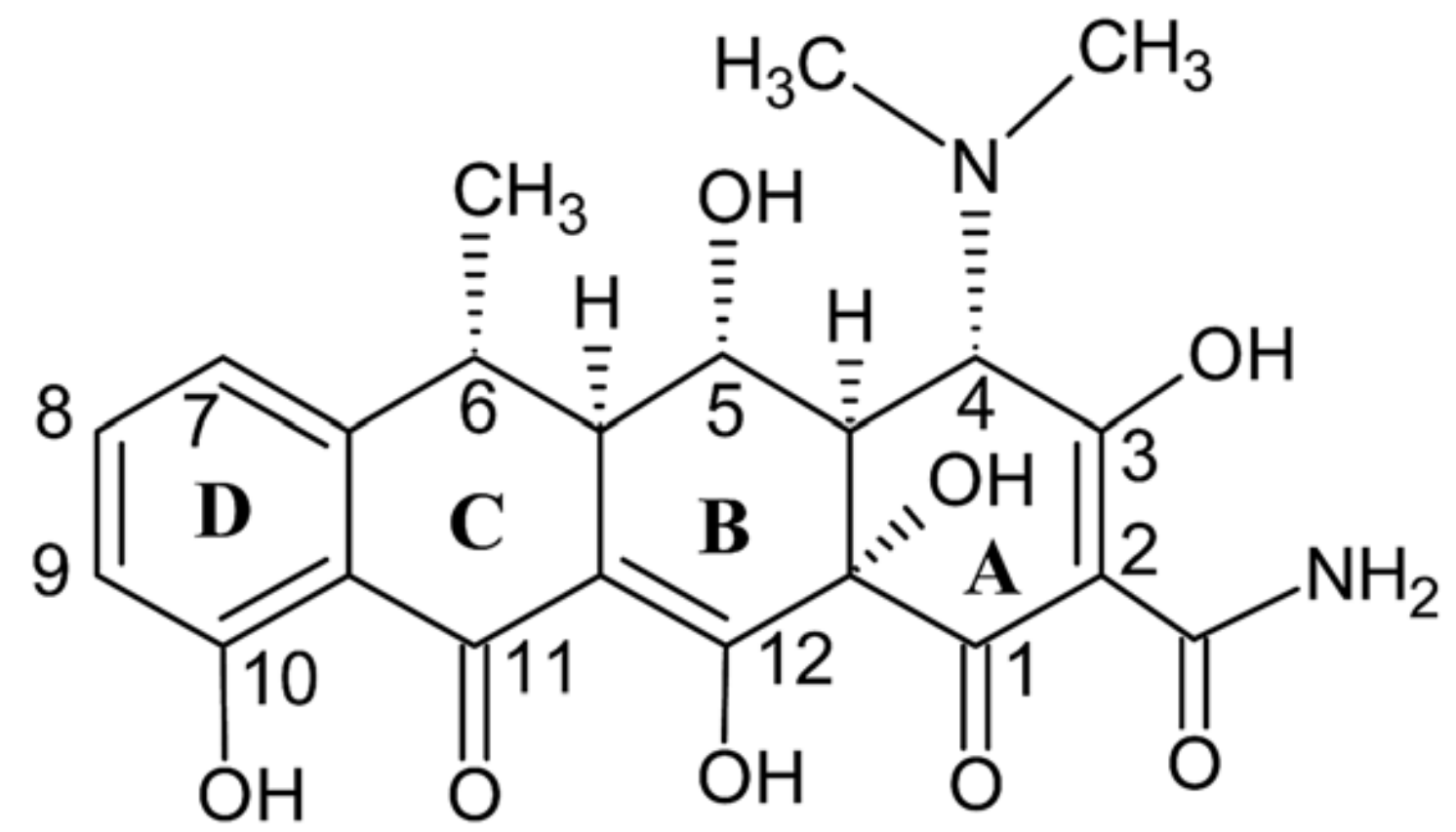

Scheme S1: Chemical structure of doxycicline (DOXY).Rings are identified with letters from A to D; this nomenclature is used for Raman band assignments. 
Table 1. Average hydrodynamic diameter and zeta potential of the prepared nanoparticles.

Note: Data are reported as mode \pm standard deviation.

\begin{tabular}{|c|c|c|c|}
\hline Particles & Particle size (nm) & PDI & Zeta potential (mV) \\
\hline DOXY-AuNPs & $11.59 \pm 0.3$ & 0.266 & $-34.70 \pm 0.8$ \\
\hline DOXY IN-AuNPs & $70.29 \pm 0.5$ & 0.330 & $-17.93 \pm 0.7$ \\
\hline DOXY ON-AuNPs & $19.94 \pm 0.6$ & 0.238 & $-25.60 \pm 0.5$ \\
\hline
\end{tabular}




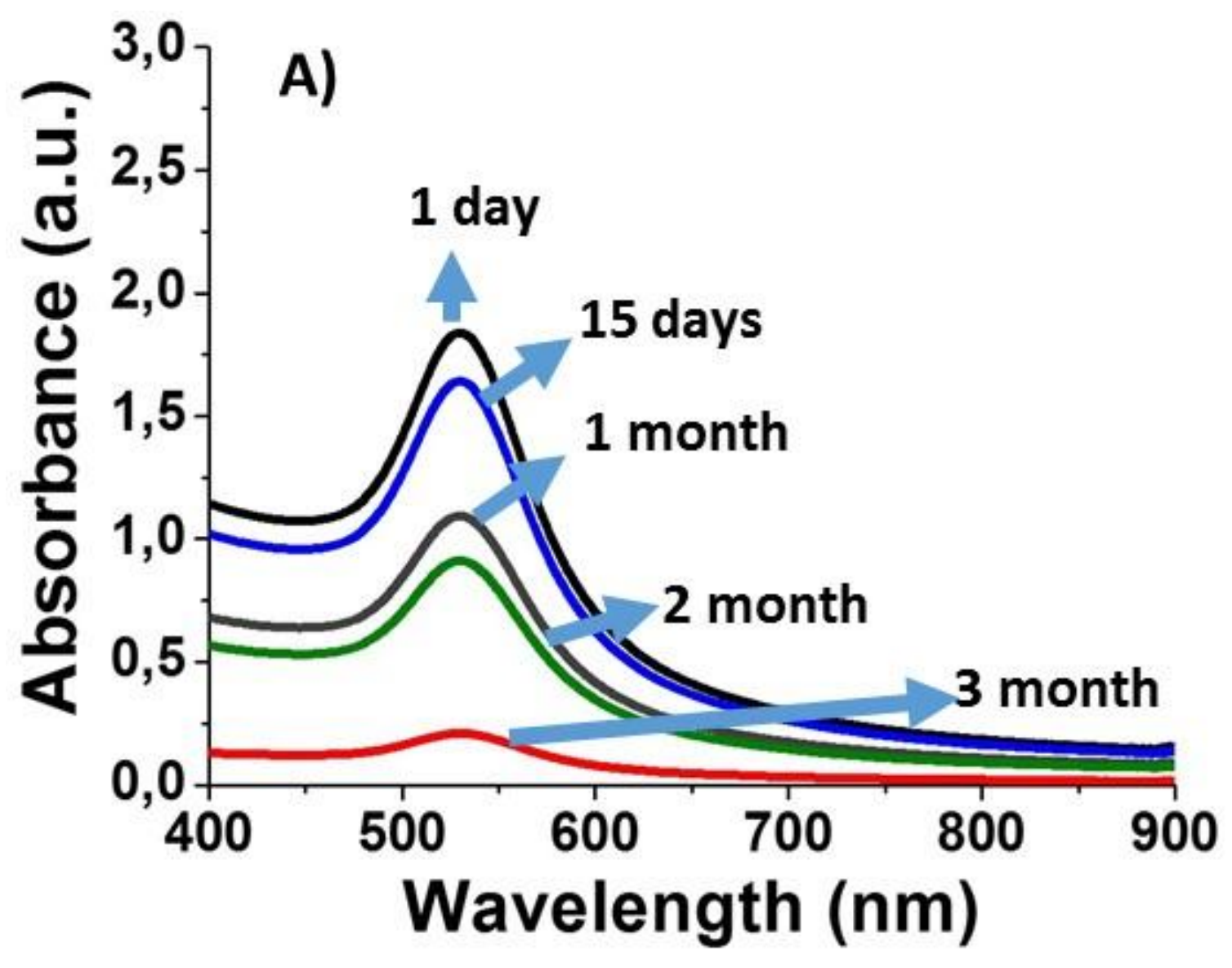




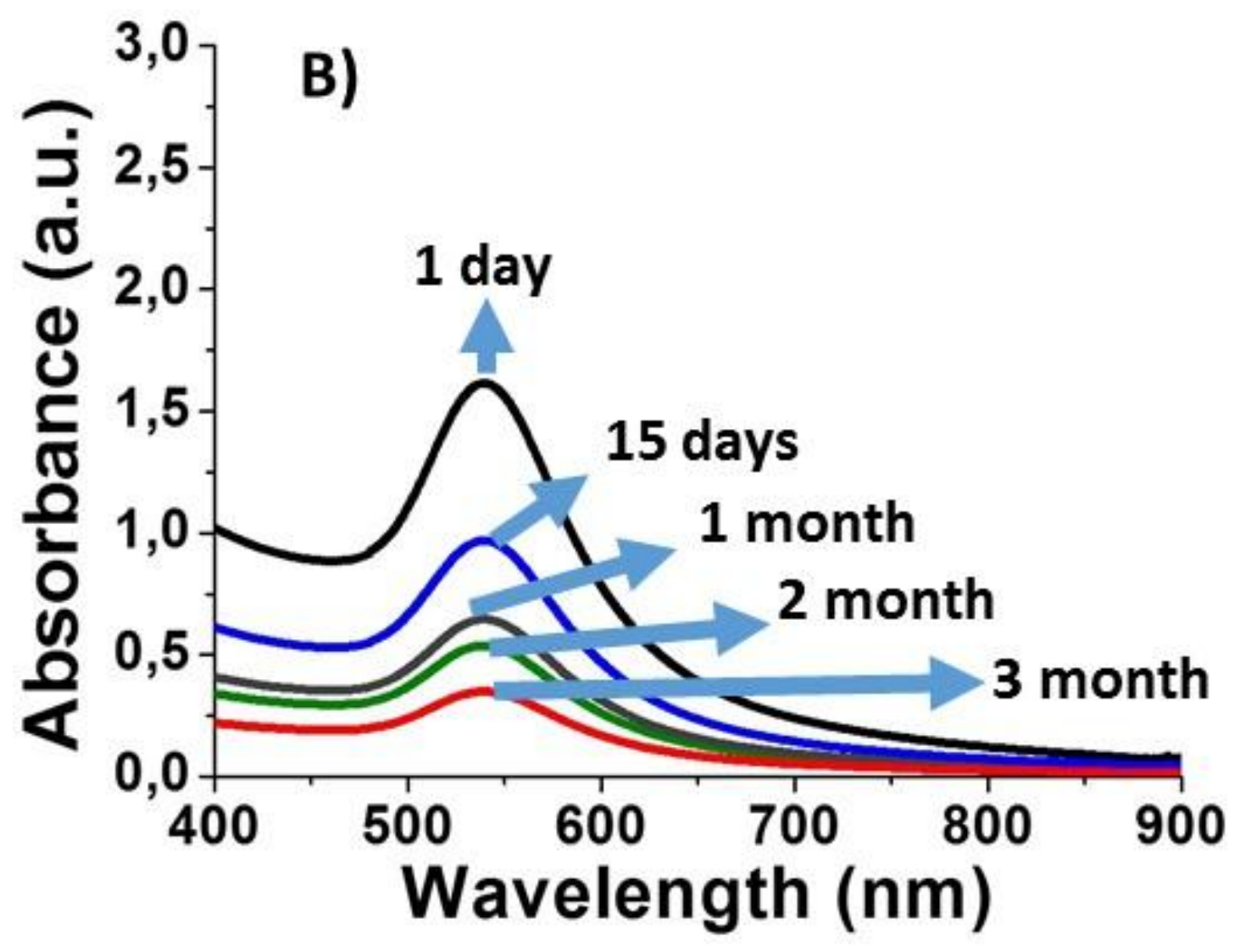




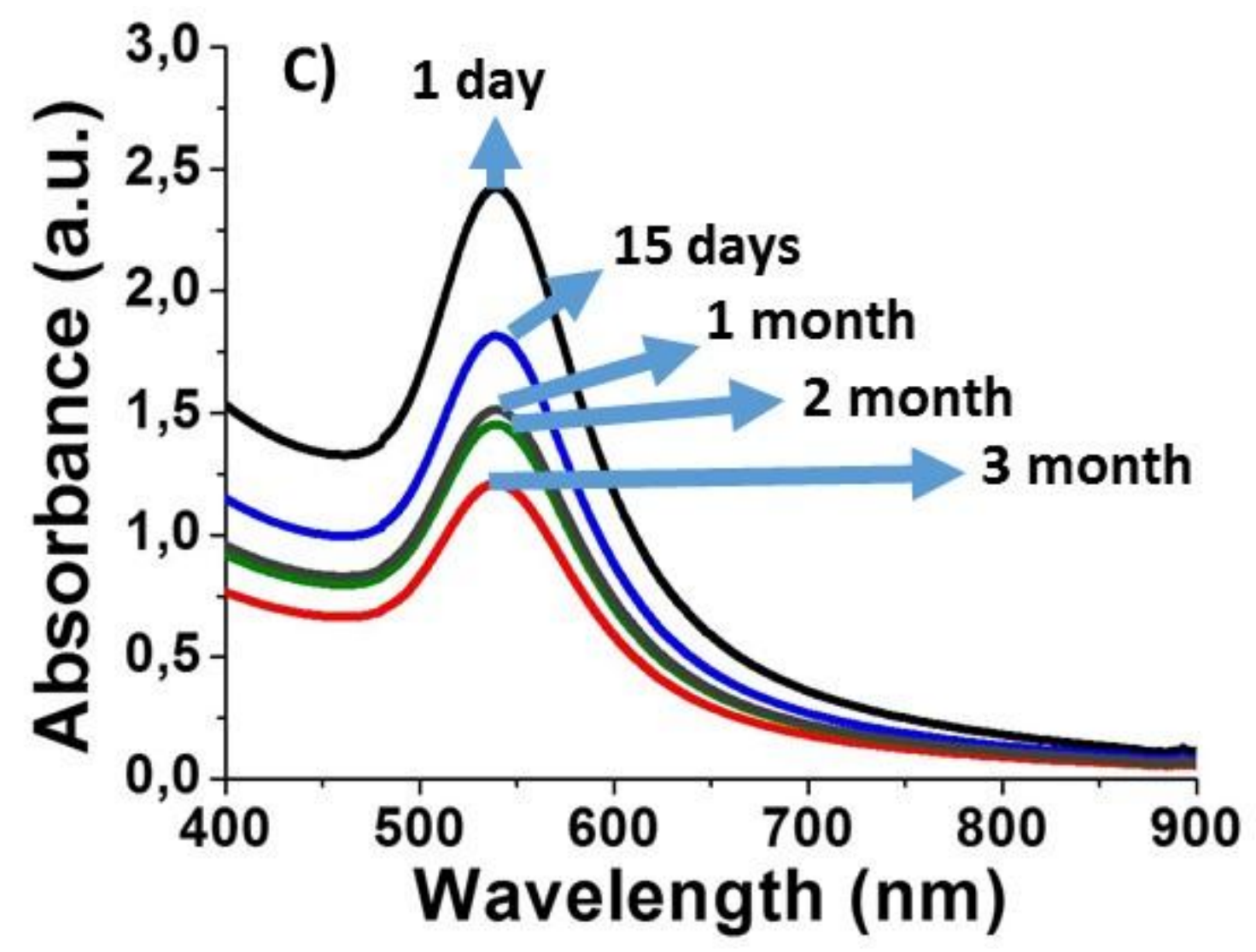

Figure S1: Changes in the UV-Vis absorption spectra of DOXY gold nanoparticles when incubated in bacterial culture media solution at pH 8, up to three months ( A: DOXY AuNPs; B: DOXY IN AuNPs; C: DOXY ON AuNPs). 
A)

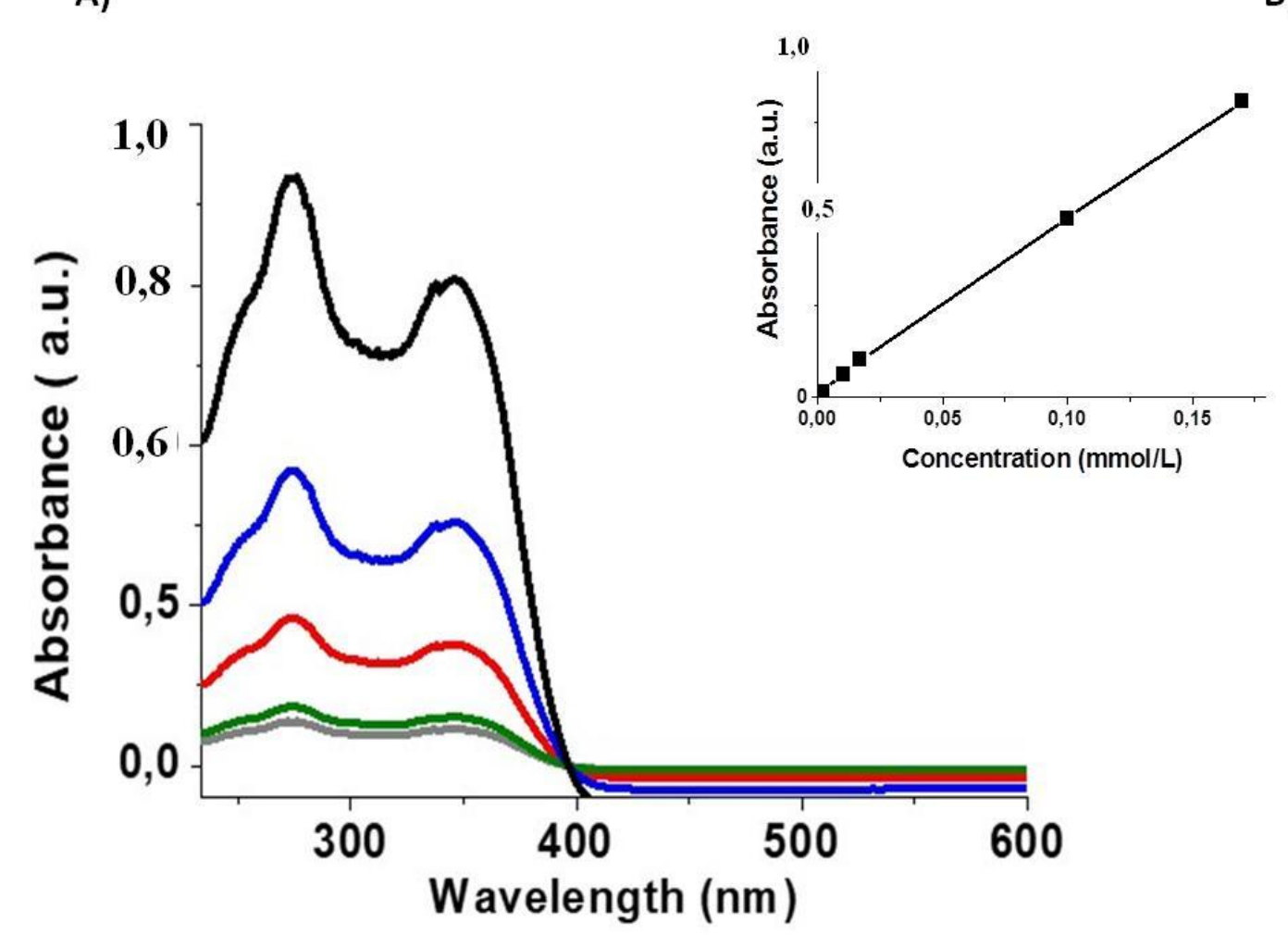

B)

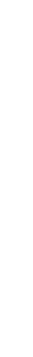

Figure S2: (a) UV-Vis absorption spectra of DOXY at increasing known concentrations. (b) A calibration curve $\left(\mathrm{R}^{2}=0.9997\right)$ was extrapolated from such measurements. The amount of DOXY molecules contained into DOXY ON AuNPs, DOXY IN AuNPS and DOXY AuNPs were estimated based on this curve. 